\title{
High Cyclability Energy Storage Device with Optimized Hydroxyethyl Cellulose-Dextran-Based Polymer Electrolytes: Structural, Electrical and Electrochemical Investigations
}

\author{
Muhammad A. S. Azha ${ }^{1}$, Elham M. A. Dannoun ${ }^{2}{ }^{\oplus}$, Shujahadeen B. Aziz ${ }^{3,4}{ }^{\oplus}$, Mohd F. Z. Kadir ${ }^{5, *}$, \\ Zaki Ismail Zaki ${ }^{6}$, Zeinhom M. El-Bahy ${ }^{7}$, Mazdida Sulaiman ${ }^{8}$ and Muaffaq M. Nofal ${ }^{9}$ (i)
}

check for updates

Citation: Azha, M.A.S.; Dannoun, E.M.A.; Aziz, S.B.; Kadir, M.F.Z.; Zaki, Z.I.; El-Bahy, Z.M.; Sulaiman, M.; Nofal, M.M. High Cyclability Energy Storage Device with Optimized Hydroxyethyl Cellulose-DextranBased Polymer Electrolytes: Structural, Electrical and Electrochemical Investigations. Polymers 2021, 13, 3602. https:// doi.org/10.3390/polym13203602

Academic Editor: Maria Assunta Navarra

Received: 2 September 2021 Accepted: 12 October 2021 Published: 19 October 2021

Publisher's Note: MDPI stays neutral with regard to jurisdictional claims in published maps and institutional affiliations.

Copyright: (c) 2021 by the authors Licensee MDPI, Basel, Switzerland. This article is an open access article distributed under the terms and conditions of the Creative Commons Attribution (CC BY) license (https:/ / creativecommons.org/licenses/by/ $4.0 /)$.
1 Institute for Advanced Studies, Universiti Malaya, Kuala Lumpur 50603, Malaysia; amirulazha96@gmail.com

2 Associate Director of General Science Department, Woman Campus, Prince Sultan University, P.O. Box 66833, Riyadh 11586, Saudi Arabia; elhamdannoun1977@gmail.com

3 Hameed Majid Advanced Polymeric Materials Research Lab, Physics Department, College of Science, University of Sulaimani, Kurdistan Regional Government, Qlyasan Street, Sulaimani 46001, Iraq; shujahadeenaziz@gmail.com

4 Department of Civil Engineering, College of Engineering, Komar University of Science and Technology, Kurdistan Regional Government, Sulaimani 46001, Iraq

5 Physics Division, Center for Foundation Studies in Science, Universiti Malaya, Kuala Lumpur 50603, Malaysia

6 Department of Chemistry, College of Science, Taif University, P.O. Box 11099, Taif 21944, Saudi Arabia; zakimohamed@tu.edu.sa

7 Department of Chemistry, Faculty of Science, Al-Azhar University, Nasr City, Cairo 11884, Egypt; zeinelbahy@azhar.edu.eg

8 Chemistry Division, Center for Foundation Studies in Science, Universiti Malaya, Kuala Lumpur 50603, Malaysia; mazdidas@um.edu.my

9 Department of Mathematics and General Sciences, Prince Sultan University, P.O. Box 66833, Riyadh 11586, Saudi Arabia; muaffaqnofal69@gmail.com

* Correspondence: mfzkadir@um.edu.my

\begin{abstract}
The preparation of a dextran (Dex)-hydroxyethyl cellulose (HEC) blend impregnated with ammonium bromide $\left(\mathrm{NH}_{4} \mathrm{Br}\right)$ is done via the solution cast method. The phases due to crystalline and amorphous regions were separated and used to estimate the degree of crystallinity. The most amorphous blend was discovered to be a blend of $40 \mathrm{wt} \%$ Dex and $60 \mathrm{wt} \%$ HEC. This polymer blend serves as the channel for ions to be conducted and electrodes separator. The conductivity has been optimized at $(1.47 \pm 0.12) \times 10^{-4} \mathrm{~S} \mathrm{~cm}^{-1}$ with $20 \mathrm{wt} \% \mathrm{NH}_{4} \mathrm{Br}$. The EIS plots were fitted with EEC circuits. The DC conductivity against 1000/T follows the Arrhenius model. The highest conducting electrolyte possesses an ionic number density and mobility of $1.58 \times 10^{21} \mathrm{~cm}^{-3}$ and $6.27 \times 10^{-7} \mathrm{~V}^{-1} \mathrm{~s}^{-1} \mathrm{~cm}^{2}$, respectively. The TNM and LSV investigations were carried out on the highest conducting system. A non-Faradic behavior was predicted from the CV pattern. The fabricated electrical double layer capacitor (EDLC) achieved 8000 cycles, with a specific capacitance, internal resistance, energy density, and power density of $31.7 \mathrm{~F} \mathrm{~g}^{-1}, 80 \Omega, 3.18 \mathrm{Wh} \mathrm{kg}^{-1}$, and 922.22 $\mathrm{W} \mathrm{kg}^{-1}$, respectively.
\end{abstract}

Keywords: solid polymer electrolyte; dextran; ammonium bromide; supercapacitors; EDLC

\section{Introduction}

Solid polymer electrolytes (SPEs) have been investigated as electrode separators or ionic conductors in energy source devices (ESDs) by researchers worldwide [1,2]. Due to its exceptional mechanical characteristics, as well as other unique properties, such as being less flammable and having a low toxicity, SPEs have been the subject of active research [3]. Biopolymers offer a successful alternative to non-biodegradable synthetic polymers because of their biocompatibility, biodegradability, and renewability [4]. Common biopolymers that are used in electrolytes are cellulose [5], gelatin [6], chitosan [7], and starch [8]. In 
recent years, green technologies have become the main focus of the research community due to awareness of the environment. This effort is to reduce the plastic waste in the ocean.

Hydroxyethyl cellulose (HEC) consists of $\beta-1,4$ glycosidic linkages that connect the glucose rings [9]. HEC is commonly acknowledged in the cosmetic, paint, and pharmaceutical industries as a thickening and gelling agent. The properties of HEC, such as excellent thermal stability and great electrochemical efficiency, have made it suitable for HEC to be a polymer electrolyte material for many applications [10]. Zhang et al. [11] have documented that two porous polyvinylidene fluoride (PVDF) layers sandwiching a thick HEC membrane has led to an enhancement of electrochemical devices due to its ability in preventing micro short circuits. This is due the hydroxyethyl group attached to HEC's cellulose backbone. In the study carried out by Li et al. [12], the preparation of a gel membrane is done through soaking the HEC membrane in an organic electrolyte composed of a $\mathrm{LiPF}_{6}$ solution in carbonate/ethyl methyl carbonate/dimethyl carbonate, which has shown that the electrolyte could uptake up to $78.3 \mathrm{wt} \%$ of the organic liquid electrolyte, also exhibiting excellent electrochemical efficiency and great ionic conductivity at room temperature. HEC can dissolve in different organic solvents, thus making HEC the polymer host for this study [13].

Dextran (Dex) is a natural polymer that is extracted from bacteria (Leuconostocmesenteroides) in a sucrose medium. Excess dextransucraseis converted into Dex [14]. There are few studies regarding the employment of Dex as the polymer host although Dex can form a transparent film. Dexpossesses many oxygen functional groups, such as hydroxyl groups $(-\mathrm{OH})$ and glycosidic linkages $(\mathrm{C}-\mathrm{O}-\mathrm{C})$ [15]. These oxygen atoms contain lone pair electrons that are beneficial for ionic conduction. Moreover, Dex has good water solubility, low toxicity, and relative inertness. Dex has been used in various applications, primarily in medical lines such as plasma expanders, blood substitutes, and bone curing [16].

The desired physical and electrical properties can be enhanced or amplified through the blending of polymers [17]. This method has resulted in polymer blend films that possess better properties than single polymer-based films. Rajendran and Mahendran [18] reported that PMMA-PVA has a higher ionic conductivity than the unblended PMMA and PVA-based electrolytes. A study by Shukur et al. $[19,20]$ has revealed that the ionic conductivity value increased when chitosan is incorporated into a starch-ammonium bromide electrolyte from $(5.57 \pm 1.88) \times 10^{-5}$ to $(9.72 \pm 0.95) \times 10^{-5} \mathrm{~S} \mathrm{~cm}^{-1}$. Phosphoric acid [21] and sulfuric acid [22] are proton donors but suffer from chemical degradation and deteriorate mechanical integrity, making them less suitable for practical applications [23]. Thus, ammonium salts are regularly reported as proton donors. The most common ammonium salts used are ammonium nitrate $\left(\mathrm{NH}_{4} \mathrm{NO}_{3}\right)$ [24], ammonium chloride $\left(\mathrm{NH}_{4} \mathrm{Cl}\right)$ [25], ammonium thiocyanate $\left(\mathrm{NH}_{4} \mathrm{SCN}\right)$ [17], and ammonium bromide $\left(\mathrm{NH}_{4} \mathrm{Br}\right)$ [26]. The highest room temperature conductivity achieved by the starch- $\mathrm{NH}_{4} \mathrm{NO}_{3}$ electrolyte is $2.83 \times 10^{-5} \mathrm{~S} \mathrm{~cm}^{-1}$ [24]. A report by Hamsan et al. [27] shows that Dex- $\mathrm{NH}_{4} \mathrm{NO}_{3}$ electrolyte obtained a conductivity of $3.00 \times 10^{-5} \mathrm{~S} \mathrm{~cm}^{-1}$. A report by Samsudin et al. [28] shows that carboxymethyl cellulose- $\mathrm{NH}_{4} \mathrm{Br}$ exhibited room temperature conductivity at $1.12 \times 10^{-4} \mathrm{~S} \mathrm{~cm}^{-1}$.

An electrical double-layer capacitor (EDLC) is one of the alternatives for energy storage device. It can be substituting the conventional chemical batteries as it relies on the energy storage mechanism that obeys the non-Faradaic reactions. Adding salt to the electrolyte produces negatively charged ions (anions) and positively charged ions (cations). Once the EDLC is attached to a power source (charging), one of the electrodes will be positive as the electric field that build around it will attract anions and repel cations. The opposite reaction will occur at the negative electrode. The strong electrical field retains ions from the electrolyte and electrons from the electrode. This is called the formation of a double layer charge where energy is stored as potential energy [29]. Instead, the opposite action takes place during the discharge process. The advantages of EDLC are easy to manufacture, safe, and cheap. Moreover, EDLCs have a longer life cycle, higher power density, more excellent reversibility, and better thermal stability, unlike Faradaic 
capacitors or pseudo capacitors [30]. This study reports the electrical behavior of Dex-HEC blend-based electrolytes incorporated with $\mathrm{NH}_{4} \mathrm{Br}$. Ammonium salt was chosen as it is reported to be suitable for low-energy-density device applications. The highest conducting electrolyte was used in EDLC as the separator of electrodes.

\section{Experimental}

\subsection{Electrolyte Preparation}

In $100 \mathrm{~mL}$ of distilled water, different amounts of HEC (Sigma Aldrich, Kuala Lumpur, Malaysia) were dissolved. Dex (Sigma Aldrich, avgmolwt 35,000-45,000) was then added after the HEC solution had been fully dissolved. The mixture was stirred until the solution became homogeneous. The most amorphous system was selected to prepare the solidbased electrolytes. Various $\mathrm{NH}_{4} \mathrm{Br}$ (Bendozen, Kuala Lumpur, Malaysia) quantities were employed to prepare the salted system in the most amorphous Dex-HEC solutions, and the mixture was stirred until complete dissolution was achieved. The solutions were cast into different Petri dishes and allowed to dry for $4-5$ days $\left(25^{\circ} \mathrm{C}\right.$, relative humidity, $\mathrm{RH} \sim 50 \%$ ). All the films were stored in a silica geldesiccator package and then coded as presented in Tables 1 and 2 .

Table 1. Designation for the polymer blend systems and their respective degree of crystallinity.

\begin{tabular}{cc}
\hline Dextran:HEC Composition $(\mathbf{w t} \%)$ & Designation \\
\hline $0: 100$ & BL0 \\
$10: 90$ & BL1 \\
$20: 80$ & BL2 \\
$30: 70$ & BL3 \\
$40: 60$ & BL4 \\
$50: 50$ & BL5 \\
$60: 40$ & BL6 \\
$70: 30$ & BL7 \\
$80: 20$ & BL8 \\
$90: 10$ & BL9 \\
$100: 0$ & BL10 \\
\hline
\end{tabular}

Table 2. Designation for the salted systems.

\begin{tabular}{|c|c|}
\hline Dextran:HEC: $\mathrm{NH}_{4} \mathrm{Br}$ Composition (wt $\%$ ) & Designation \\
\hline $40: 60: 0$ & BL4 \\
\hline $38: 57: 5$ & SL1 \\
\hline $36: 54: 10$ & SL2 \\
\hline $34: 51: 15$ & SL3 \\
\hline $32: 48: 20$ & SL4 \\
\hline $30: 45: 25$ & SL5 \\
\hline $28: 42: 30$ & SL6 \\
\hline
\end{tabular}

\subsection{Electrolyte Characterization}

For the XRD analysis, a Siemens D5000 X-ray diffractometer (1.5406 $\AA$ ) (Malvern Panalytical Ltd., Malvern, UK) was used. The angle of $2 \theta$ varied from $5^{\circ}$ to $80^{\circ}$ with a resolution of $0.1^{\circ}$. The degree of electrolyte crystallinity $\left(\chi_{c}\right)$ was checked with

$$
\chi_{c}=\frac{A_{c r y}}{A_{s}} \times 100 \%
$$

where the areas are defined as $A_{s}$ and $A_{c r y}$, for the sum of the hump and crystalline peaks, respectively. The deconvolution method (OriginPro8 Software) was used to calculate the areas of the peaks.

The impedance study was performed using the frequency range between $50 \mathrm{~Hz}$ and $5 \mathrm{MHz}$ using a HIOKI 3532-50 LCR HiTESTER (HIOKI, Nagano, Japan) at room 
temperature. An AC voltage of the peak-to-peak amplitude of $10 \mathrm{mV}$ was superimposed onto the DC voltage of $40 \mathrm{mV}$. The electrolytes were sandwiched between two electrodes made of stainless steel. The electrolyte's conductivity was determined using the following formula:

$$
\sigma=d \times R_{b}^{-1} A^{-1}
$$

where $R_{b}$ denotes the bulk resistance, $A$ stands for the electrolyte-electrode contact surface area, and $d$ is the electrolyte's thickness. The results of the impedance analysis were also employed in the dielectric study analysis. The stability of the electrolyte against the applied potential was measured using linear sweep voltammetry (LSV) analysis at a sweep rate of $5 \mathrm{mV} \mathrm{s}^{-1}$. Cyclic voltammetry $(\mathrm{CV})$ was also performed to show the capacitive behavior of the sample at various scan rates. The cell was connected to the three electrode systems, namely, the counter electrode, working electrode, and reference electrode, using a Digi-IVY DY2300 potentiostat. The current was measured between the working electrode and the counter electrode while the potential was measured between the reference electrode and the working electrode.

\subsection{EDLC Preparation}

The EDLC was constructed using carbon black, PVDF, and activated carbon. Under gentle stirring, $0.50 \mathrm{~g}$ of PVDF was incorporated into $15 \mathrm{~mL}$ of $\mathrm{N}$-methyl pyrrolidone (NMP). Using a planetary ball miller, a mixed powder was created by mixing $0.25 \mathrm{~g}$ of black carbon with $3.25 \mathrm{~g}$ of activated carbon. After that, the mixed powder was added to the NMP-PVDF solution. The mixture was then cast on an aluminum foil with a doctor blade and heated for a certain amount of time at $60^{\circ} \mathrm{C}$. To eliminate excess moisture, the electrodes were placed in a desiccator containing silica gel. An area of $2.01 \mathrm{~cm}^{2}$ was taken out of the electrode. The highest conductive electrolyte was sandwiched between two electrodes, then packed into a CR2032 coin cell. The electrode had a thickness of $0.0025 \mathrm{~cm}$. At a potential range of 0 to $0.9 \mathrm{~V}$ and a sweep rate of $5,10,20,50$, and $100 \mathrm{mV} \mathrm{s}{ }^{-1}$, the Digi-IVY DY2300 potentiostat was utilized to conduct cyclic voltammetry (CV) analysis.

\section{Result and Discussion}

3.1. Ideal Composition for the Polymer Blend Host of the Electrodes Separator

Figure 1 shows the XRD patterns of the polymer blends. The pattern of the XRD for BL0 has two humps at $2 \theta=15.8^{\circ}$ and $22.64^{\circ}$, where the peak at $15.8^{\circ}$ is less prominent. This is a typical XRD pattern of semi-crystalline materials. As more Dex is added into the polymer blend, these two peaks changed their intensity and position. The trend inthe XRD pattern moved towards the pattern of BL10 as more Dex was added. This indicates that the oxygen-containing functional groups of Dex and hydrogen in the structure of HEC, or vice versa, have formed an interaction via hydrogen bonding. Furthermore, it is a sign that the crystalline structure in the blend has been reduced [31]. From the plot in Figure 1, BL4 has the most negligible intensity among other blends, which signifies that BL4 has the most amorphous structure compared to the other blends. However, this statement has to be further confirmed through the deconvolution technique as it helps to separate any potential amorphous and crystalline peaks that may overlap. In this method, prominent peaks signify amorphous regions, while the narrow peaks indicate that the region is crystalline [32]. 


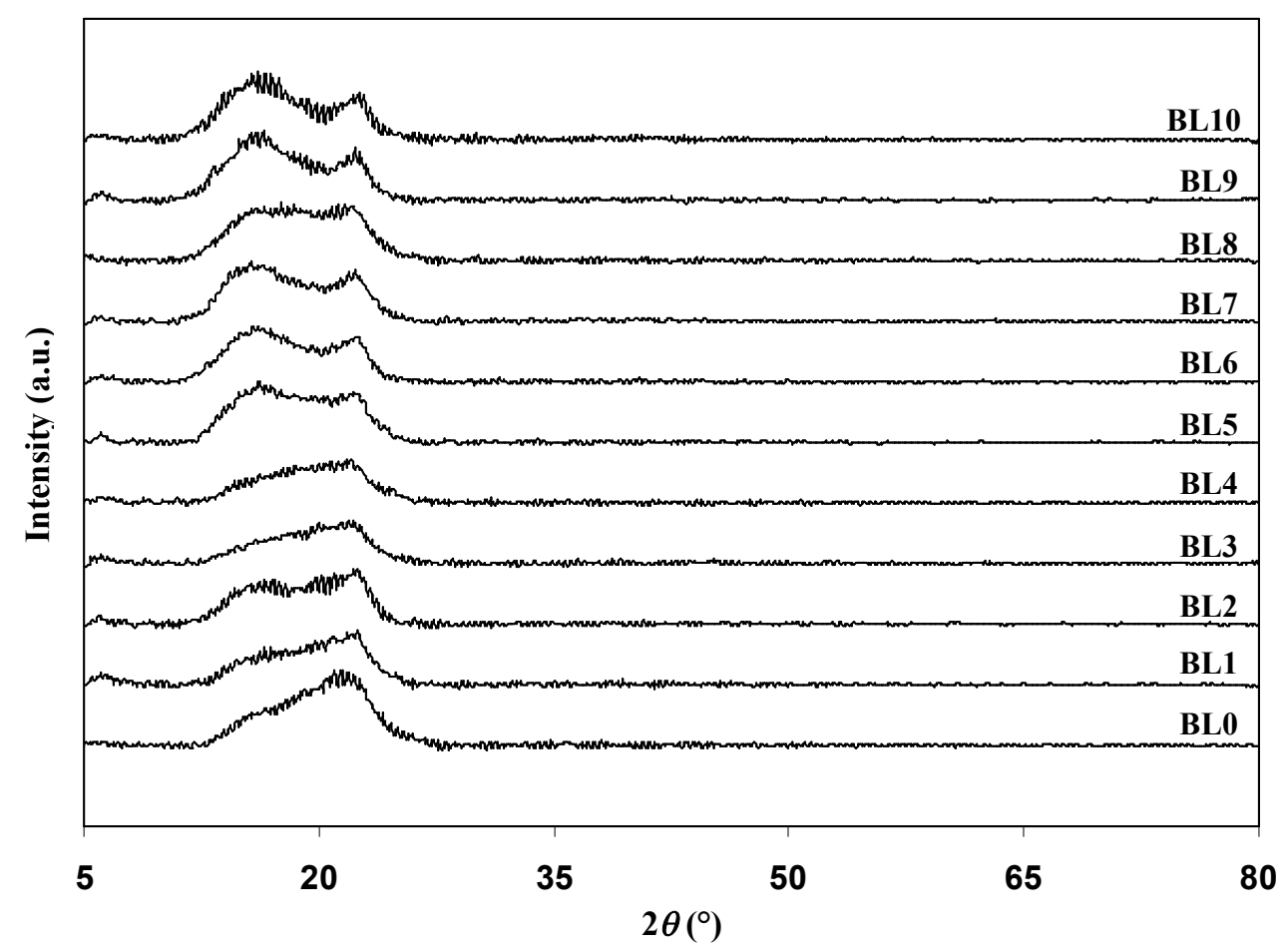

Figure 1. XRD patterns for the polymer blend.

Figure 2 shows the deconvoluted XRD patterns of the chosen polymer blend films. BL0 and BL10 can serve as the references for detecting changes in the peak position or intensity in the diffractogram of the polymer blends. The XRD pattern of BL0 has three crystalline peaks at $2 \theta=15.8^{\circ}, 19.8^{\circ}$, and $22.64^{\circ}$, as well as two amorphous peaks at $2 \theta$ $=20.0^{\circ}$ and $40.0^{\circ}$. This finding is similar to the results obtained by Hanif et al. [33]. In another study [34], for BL10, three crystalline peaks at $2 \theta=15.8^{\circ}, 19.0^{\circ}$, and $22.5^{\circ}$ and two amorphous peaks at $2 \theta=20.0^{\circ}$ and $40.0^{\circ}$ have similarly appeared [34]. The XRD pattern in BL4 indicates a reduction in the intensity of three crystalline peaks at $2 \theta=15.8^{\circ}, 19.0^{\circ}$, and $22.5^{\circ}$, indicating the increase in amorphousness of the blend. Equation (1) calculates the degree $\chi_{\mathrm{c}}$, and the results are tabulated in Table 3. BL4 blend has the most amorphous blend as it displays the lowest $\chi_{\mathrm{c}}$; therefore, the blend of $40 \mathrm{wt} \%$ Dex and $60 \mathrm{wt} \%$ HEC is chosen as the polymer host.

Table 3. Designation for the polymer blend systems and their respective degree of crystallinity.

\begin{tabular}{cc}
\hline Designation & Degree of Crystallinity $\left(\chi_{c}\right)$ \\
\hline BL0 & 30.53 \\
BL1 & 29.97 \\
BL2 & 28.57 \\
BL3 & 24.44 \\
BL4 & 20.17 \\
BL5 & 24.59 \\
BL6 & 28.52 \\
BL7 & 29.02 \\
BL8 & 29.93 \\
BL9 & 30.88 \\
BL10 & 32.06 \\
\hline
\end{tabular}




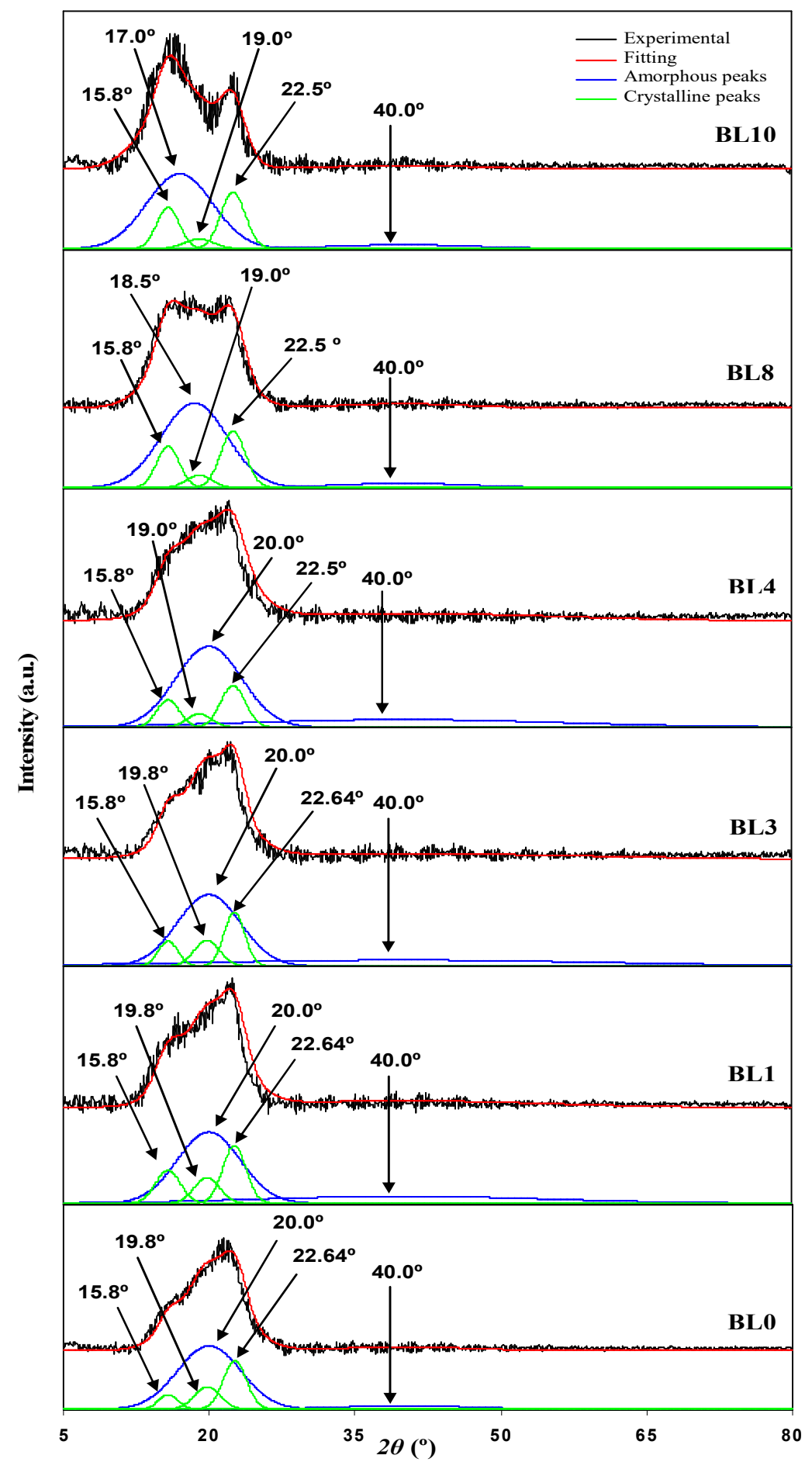

Figure 2. Deconvoluted XRD patterns for the polymer blend.

\subsection{Conductivity Analysis}

Figure 3 displays the variation in room temperature DC conductivity (with error bars) when the $\mathrm{NH}_{4} \mathrm{Br}$ content is changed. It is observed that the conductivity increases from $(2.04 \pm 0.57) \times 10^{-8}$ to $(2.42 \pm 0.54) \times 10^{-7} \mathrm{~S} \mathrm{~cm}^{-1}$ as $5 \mathrm{wt} \%$ of $\mathrm{NH}_{4} \mathrm{Br}$ is added into the Dex-HEC host. It can be seen that the conductivity value has been maximized up to $(1.47 \pm 0.12) \times 10^{-4} \mathrm{~S} \mathrm{~cm}^{-1}$ with the inclusion of $20 \mathrm{wt} \% \mathrm{NH}_{4} \mathrm{Br}$ into the polymer host. This inclination in the conductivity value is a result of the increment in the charge carrier [24]. However, the trend stops at $20 \mathrm{wt} \% \mathrm{NH}_{4} \mathrm{Br}$ content. Any increment surpassing the $20 \mathrm{wt} \%$ of $\mathrm{NH}_{4} \mathrm{Br}$ content leads to a decreasing conductivity value. This finding 
was verified by Mohamed et al. [35], who concluded that the reduction in conductivity value is due to ion pairs, ion triplets, and higher ion aggregations, which significantly reduce the mobility and ionic number density. The variation in conductivity for the salted electrolytes as a function of temperature is depicted in Figure 4. Conductivity is observed to increase with the rise of the temperature. Due to the linear relation between conductivity and temperature $\left(\mathrm{R}^{2} \sim 0.97-0.99\right)$, all electrolytes in this study obey the Arrhenius law. Therefore, the polymer host structure does not have a phase transition when the salt is added [36]. The equation of Arrhenius is given as

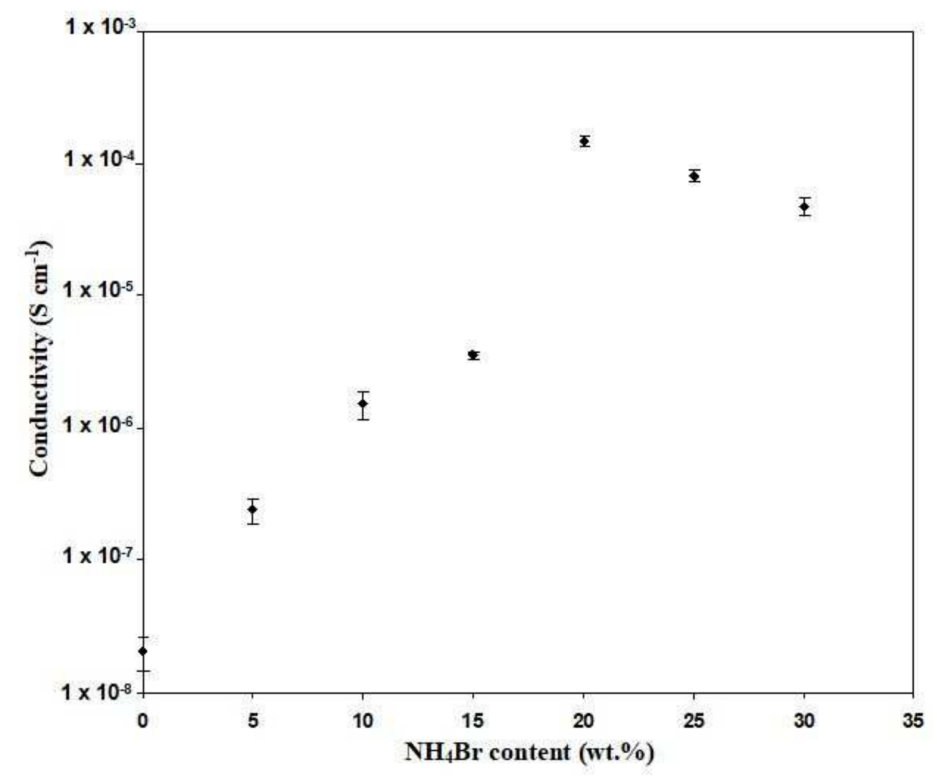

Figure 3. Conductivity versus $\mathrm{NH}_{4} \mathrm{Br}$ content at room temperature.

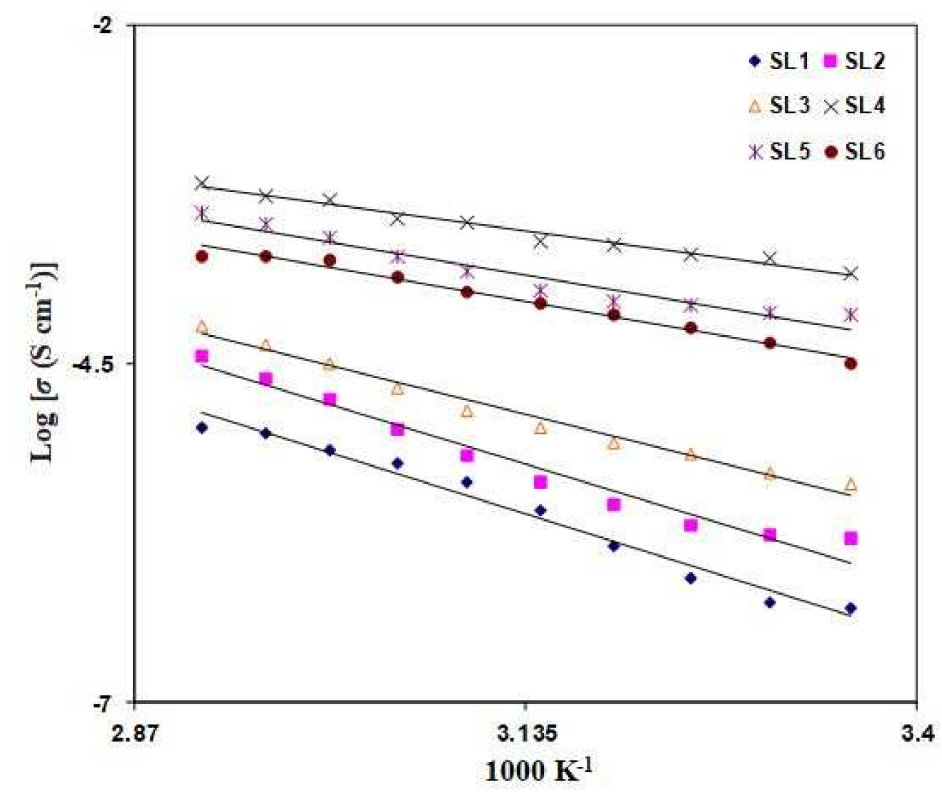

Figure 4. Conductivity at various temperatures for the salted electrolytes.

$$
\sigma=\sigma_{o} \exp \left(-\frac{E_{a c}}{k T}\right)
$$

where $E_{a c}$ is the ion activation energy for the migration from one site to another, $k$ is the Boltzmann constants, $\sigma_{o}$ stands for a pre-exponential component, and $T$ is the absolute 
temperature. Other proton-based polymer electrolyte studies have also reported Arrhenius behavior, such as PVA-NH${ }_{4} \mathrm{SCN}$ [37], MC-PVA- $\mathrm{NH}_{4} \mathrm{NO}_{3}$ [38], and $\mathrm{PVA}-\mathrm{NH}_{4} \mathrm{Cl}$ [23]. The plot slope in Figure 4 is used to evaluate $E_{a c}$. As illustrated in Table 4, the $E_{a c}$ value is 0.68 when $5 \mathrm{wt} \% \mathrm{NH}_{4} \mathrm{Br}$ is infused and further decreases to 0.26 with the presence of $20 \mathrm{wt} \% \mathrm{NH}_{4} \mathrm{Br}$. Sohaimy et al. [39] reported that the highest conducting electrolyte, carboxymethylcellulose $(\mathrm{CMC})$ doped with ammonium carbonate $\left(\left(\mathrm{NH}_{4}\right)_{2} \mathrm{CO}_{3}\right)$, has the lowest $E_{a c}$ value. The number density of ions in the electrolyte increases as the $\mathrm{NH}_{4} \mathrm{Br}$ concentration rises, reducing the energy barrier [40]. As a result, the increased conductivity value is explained. In the transport section, the rise in conductivity with rising temperature will be discussed further.

Table 4. The value of $E_{a c}$ for the salted electrolytes.

\begin{tabular}{cc}
\hline Electrolyte & $E_{a c}(\mathbf{e V})$ \\
\hline SL1 & 0.68 \\
SL2 & 0.65 \\
SL3 & 0.54 \\
SL4 & 0.26 \\
SL5 & 0.38 \\
SL6 & 0.61 \\
\hline
\end{tabular}

\subsection{Impedance Analysis}

Figure 5 displays the Nyquist plot for SL1, SL2, SL3, SL4, SL5, and SL6 at room temperature. SL1 (Figure 5a) shows a semicircle and spike. $R_{b}$ can be obtained from the interception of the semicircle and spike. Ionic migration in the bulk of electrolytes caused the shape of the semicircle at higher frequencies while the spike at low frequencies indicates a polarization effect [41]. As the concentration of salt increases, theSL2 and SL3 semicircles decreased; this denotes that there are more ions available. Thus, more ions can travel from one electrode to the other, as the concentration of $\mathrm{NH}_{4} \mathrm{Br}$ increases [42]. As seen in Figure $5 \mathrm{~d}$, the addition of $20 \mathrm{wt} \% \mathrm{NH}_{4} \mathrm{Br}$ (SL4) resulted in the disappearance of the semicircle. Compared with the previous SL1, $R_{b}$ is taken from the intersection point of the spike and horizontal axis. Shukur [43] stated that the disappearance of the semicircle is due to the dominance of resistive parts of the polymer. This condition also suggests that there is an increment in the number density of ions. The $R_{b}$ value for SL5 and SL6 increase, implying that the salt was recrystallized [44]. This means that the conductivity value of SL5 and SL6 is lower than SL4. The SL4 electrolyte is selected for impedance analysis at different temperatures, as shown in Figure 6. The increment in temperature leads to a decrease in the $R_{b}$ value. The temperature enhances the salt dissociation and the segmental movement of the polymer as well [45]. Hence, the electrolyte conductivity will be increased as the temperature rises. 
a)

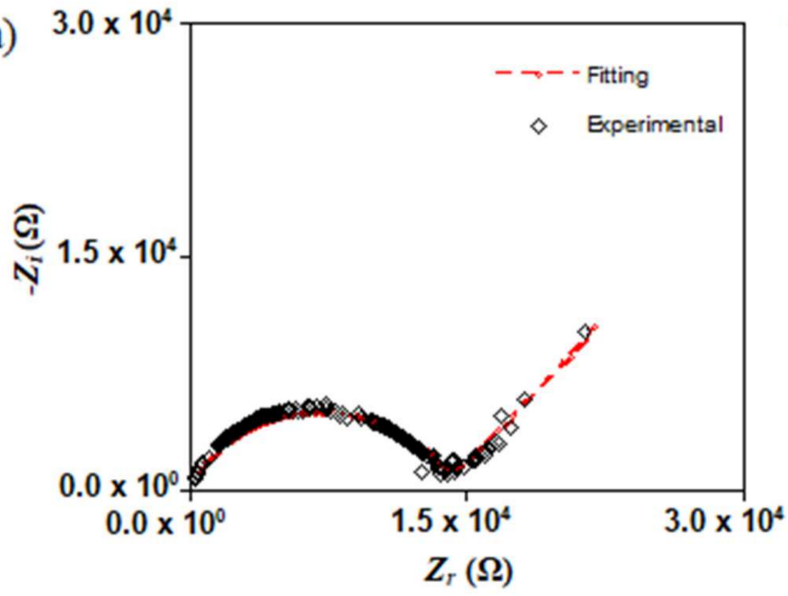

c)

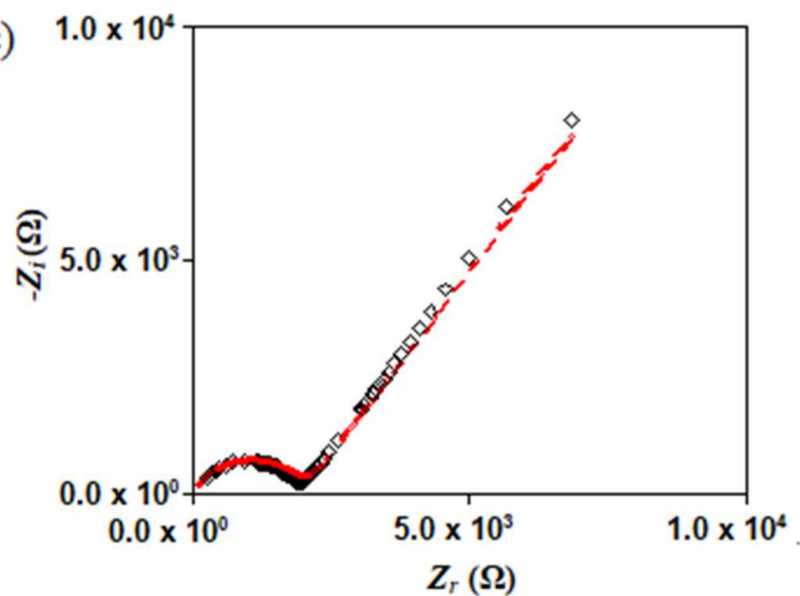

e)

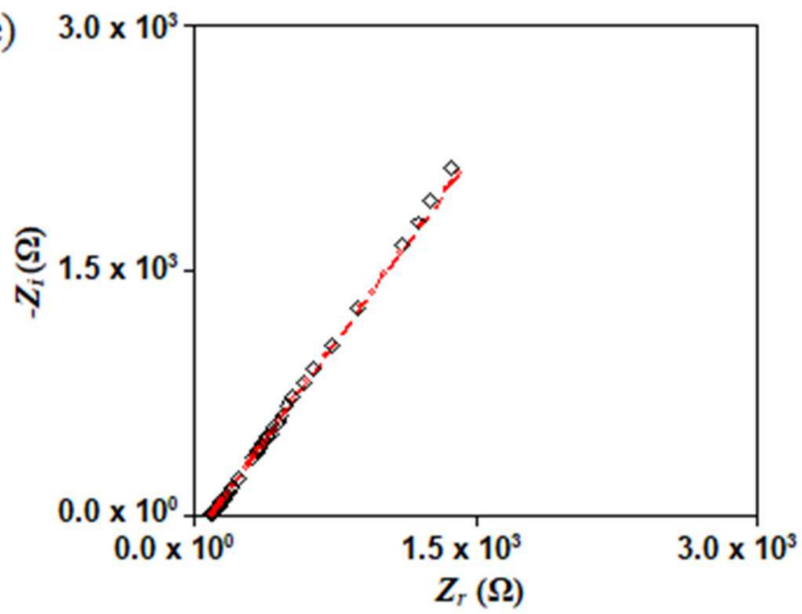

b)

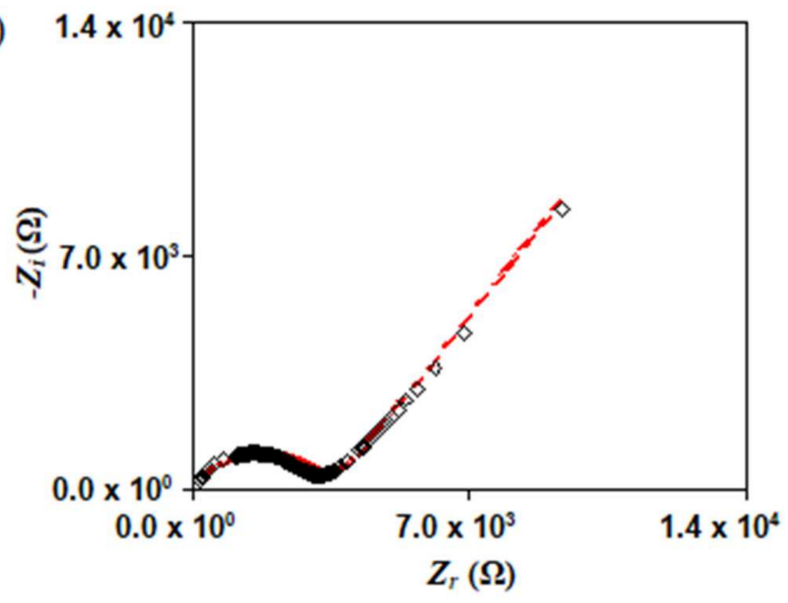

d)
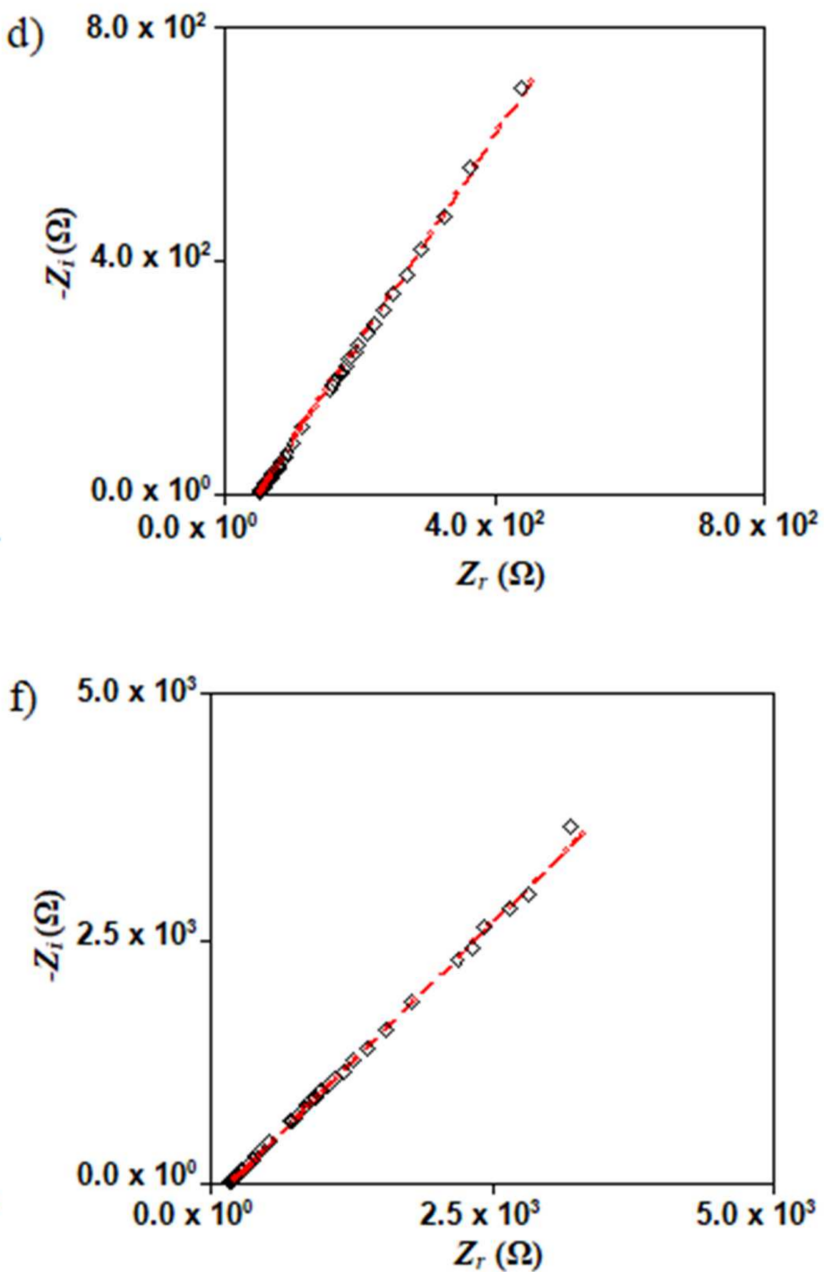

Figure 5. Nyquist plot for (a) SL1, (b) SL2, (c) SL3, (d) SL4, (e) SL5 and (f) SL6 at room temperature. 
a)

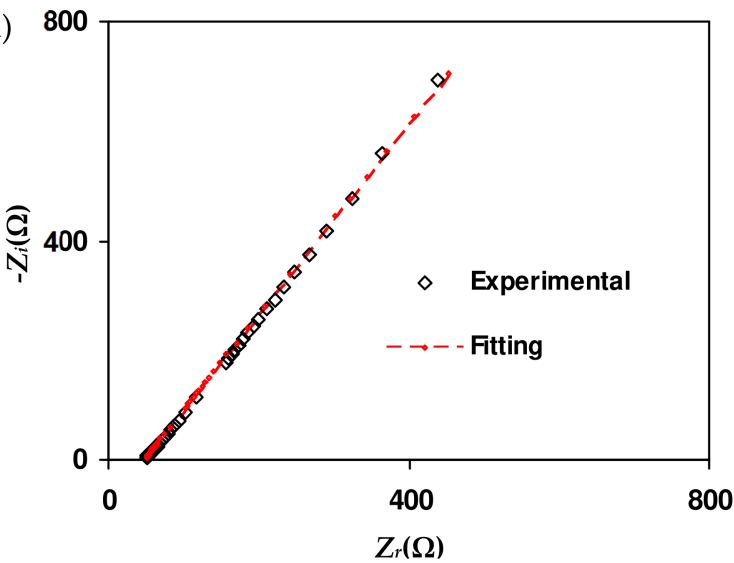

c)

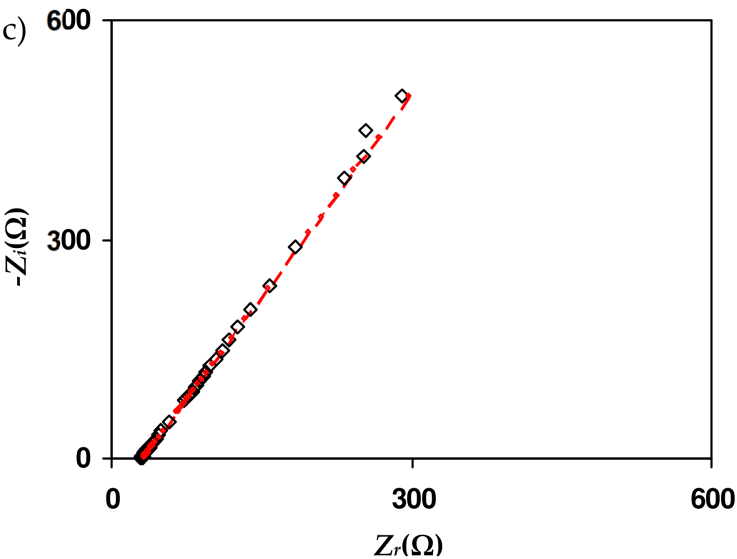

e)

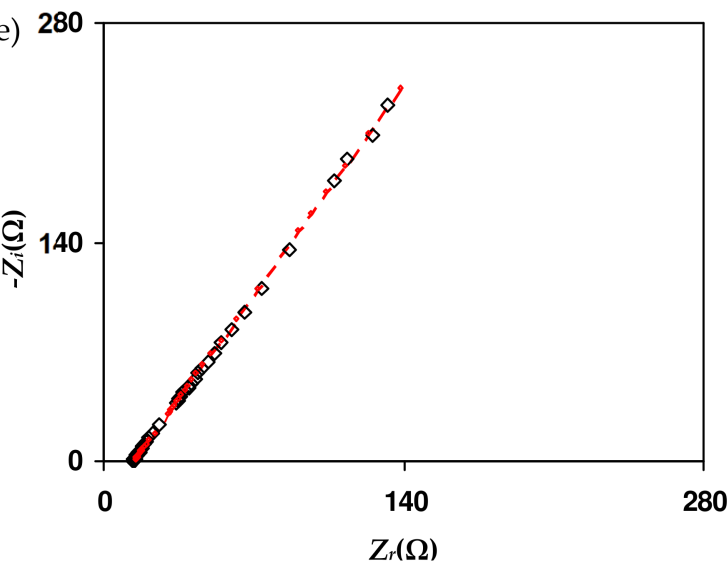

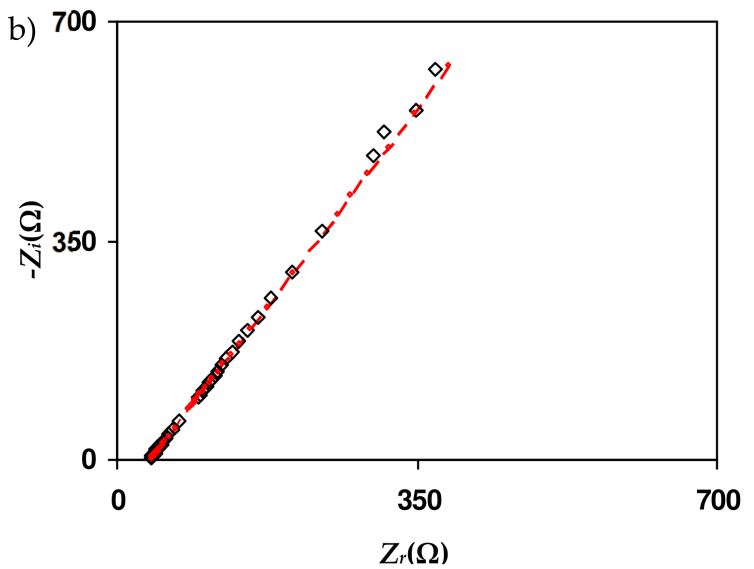

d)
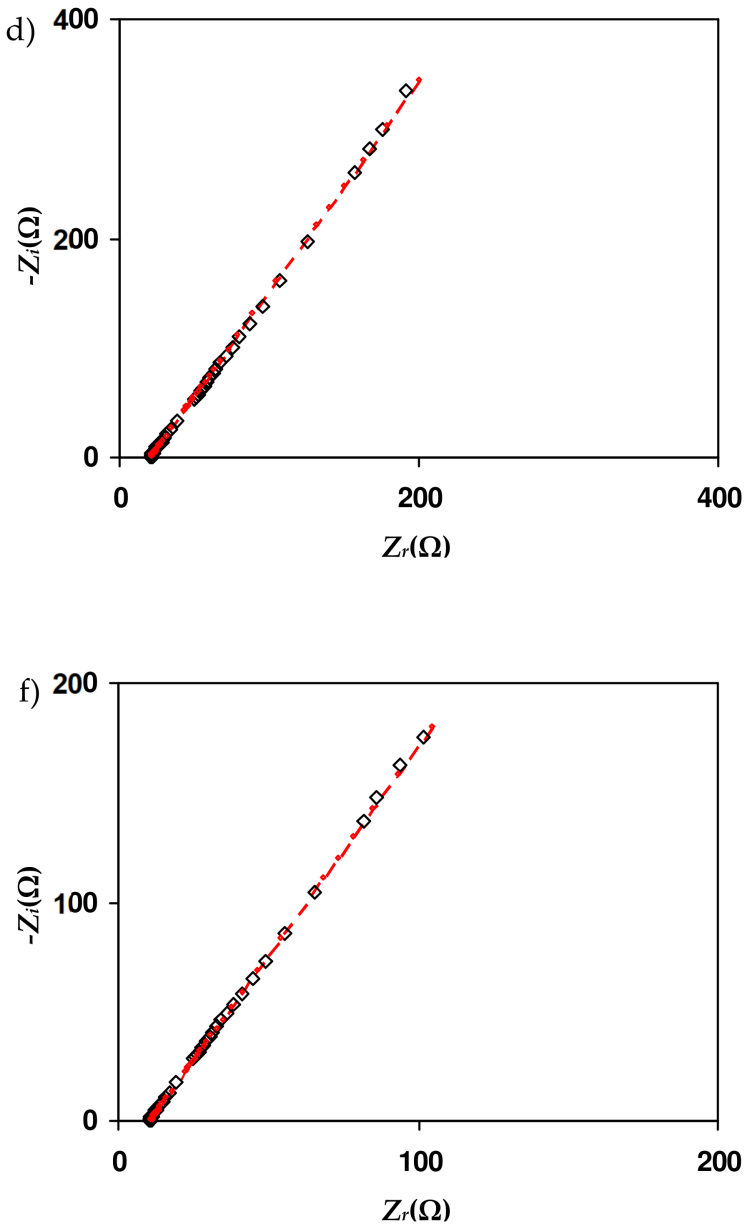

Figure 6. Nyquist plot for SL4 at (a) 298K, (b) 303K, (c) 313K, (d) $323 \mathrm{~K}$, (e) $333 \mathrm{~K}$ and (f) $343 \mathrm{~K}$.

The equivalent electrical circuit is used because it gives an easy and direct picture of the device. Figure 7a,b shows the corresponding circuit for the semicircle-spike and spike plots, respectively. Due to the electrolyte's inhomogeneity, it was categorized as an "imperfect capacitor", known as the constant-phase element (CPE). CPE is given as [46]

$$
Z_{C P E}=\frac{1}{C \omega^{p}}\left[\cos \left(\frac{\pi p}{2}\right)-i \sin \left(\frac{\pi p}{2}\right)\right]
$$

where $p$ relates to the plot's deviation from the axis. $Z_{i}$ and $Z_{r}$ are the imaginary and real parts of the impedance, respectively. $C$ is the CPE's capacitance, while $\omega$ is the radial 
frequency. The circuit in Figure 7a (for the spike and semicircle) can be expressed via the following equations:

$$
\begin{aligned}
& Z_{r}=\frac{R_{b} C_{1} \omega^{p 1} \cos \left(\frac{\pi p_{1}}{2}\right)+R_{b}}{2 R_{b} C_{1} \omega^{p} \cos \left(\frac{\pi p}{2}\right)+R_{b}{ }^{2} C^{2} \omega^{2 p}+1}+\frac{\cos \left(\frac{\pi p_{2}}{2}\right)}{C_{2} \omega^{p 2}} \\
& Z_{i}=\frac{R_{b} C_{1} \omega^{p 1} \sin \left(\frac{\pi p_{1}}{2}\right)}{2 R_{b} C_{1} \omega^{p} \cos \left(\frac{\pi p}{2}\right)+R_{b}{ }^{2} C^{2} \omega^{2 p}+1}+\frac{\sin \left(\frac{\pi p_{2}}{2}\right)}{C_{2} \omega^{p 2}}
\end{aligned}
$$

where $p_{2}$ is the spike deviation from the horizontal axis and $p_{1}$ is the spike deviation from the vertical axis for semicircle deviation. $C_{1}$ and $C_{2}$ are related to the high- and low-frequency capacitance, respectively. As shown in Figure $7 \mathrm{~b}$, the impedance plot with a spike has a circuit of series combination between $R_{b}$ and CPE. This set of impedance can be expressed in these equations:

$$
\begin{gathered}
Z_{r}=\frac{\cos \left(\frac{\pi p}{2}\right)}{C \omega^{p}}+R_{b} \\
Z_{i}=\frac{\sin \left(\frac{\pi p}{2}\right)}{C \omega^{p}}
\end{gathered}
$$

The circuit elements for salted electrolytes with various circuit element parameters have been determined and are shown in Tables 5 and 6 . Based on Table 5 , the $C$ value is higher at a low frequency than at a high frequency. This phenomenon is consistent with the following equation:

$$
C=\frac{A \varepsilon_{o} \varepsilon_{r}}{d}
$$

In this equation, $\varepsilon_{r}$ and $\varepsilon_{0}$ stand for the dielectric constant and vacuum permittivity, respectively. The value of $\varepsilon_{r}$ is low at a high frequency, which, successively, gives a low value of $C$ [47]. Dielectric information will be further explained in the dielectric section. It is observed that the value of $C$ increases as more salt is incorporated. The high value of $C$ indicates that more ions are produced at a high concentration of salt. Table 6 shows the circuit element of SL4 at 298, 303, 313, 323, 333, and $343 \mathrm{~K}$, respectively. The increase in C at a higher temperature is due to the enhancement of mobile ions at a high temperature. Shuhaimi et al. [48] stated that the rise in $C$ value with increasing temperature means that the electrolyte is suitable for the implementation in technologies of electrochemical devices.

a)

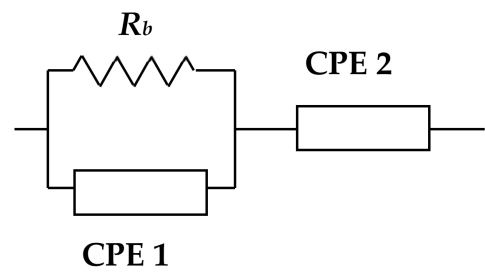

b)

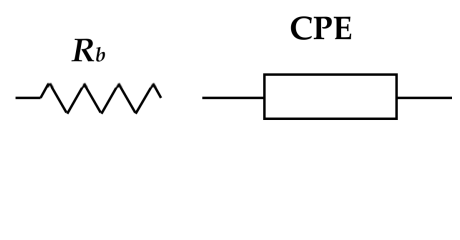

Figure 7. Equivalent circuit for (a) the semicircle-spike plot and (b) spike plot. 
Table 5. Room temperature circuit elements for the salted electrolytes.

\begin{tabular}{ccccc}
\hline Electrolyte & $\boldsymbol{k}_{\mathbf{1}}\left(\mathbf{F}^{-\mathbf{1}}\right)$ & $\left.\boldsymbol{k}_{\mathbf{2}} \mathbf{( F}^{-\mathbf{1}}\right)$ & $\boldsymbol{C}_{\mathbf{1}} \mathbf{( F )}$ & $\boldsymbol{C}_{\mathbf{2}} \mathbf{( F )}$ \\
\hline SL1 & $8.00 \times 10^{8}$ & $3.70 \times 10^{5}$ & $1.25 \times 10^{-9}$ & $2.70 \times 10^{-6}$ \\
SL2 & $1.40 \times 10^{8}$ & $3.68 \times 10^{5}$ & $7.14 \times 10^{-9}$ & $2.72 \times 10^{-6}$ \\
SL3 & $1.20 \times 10^{8}$ & $3.65 \times 10^{5}$ & $8.33 \times 10^{-9}$ & $2.74 \times 10^{-6}$ \\
SL4 & - & $3.80 \times 10^{4}$ & - & $2.63 \times 10^{-5}$ \\
SL5 & - & $9.50 \times 10^{4}$ & - & $1.05 \times 10^{-5}$ \\
SL6 & - & $1.02 \times 10^{5}$ & - & $9.80 \times 10^{-6}$ \\
\hline
\end{tabular}

Table 6. High temperature circuit elements for the SL4 electrolyte.

\begin{tabular}{ccc}
\hline Temperature (K) & $\boldsymbol{k}\left(\mathbf{F}^{-\mathbf{1}}\right)$ & $\boldsymbol{C} \mathbf{( F )}$ \\
\hline $\mathbf{2 9 8}$ & $3.80 \times 10^{4}$ & $2.63 \times 10^{-5}$ \\
303 & $3.55 \times 10^{4}$ & $2.82 \times 10^{-5}$ \\
313 & $2.92 \times 10^{4}$ & $3.42 \times 10^{-5}$ \\
323 & $2.10 \times 10^{4}$ & $4.76 \times 10^{-5}$ \\
333 & $1.45 \times 10^{4}$ & $6.90 \times 10^{-5}$ \\
343 & $1.10 \times 10^{4}$ & $9.09 \times 10^{-5}$ \\
\hline
\end{tabular}

\subsection{Determination of Transport Parameters}

Transport analysis is a pivotal study as it identifies the value of the mobility $(\mu)$ of ions and the number density $(n)$. The conductivity value is affected by these two parameters, $n$ and $\mu$, as shown in the following equation:

$$
\sigma=n e \mu
$$

where $e$ is the electronic charge. The Arof-Noor (A-N) method is used to study the transport properties of electrolytes [49]. By utilizing the A-N method, it enables us to determine the transport properties of impedance analysis. The $\mu$ value is expressed as:

$$
\mu=e D / k T
$$

where the coefficient of diffusion $(D)$ for impedance plots with a combination of a semicircle and spike can be described as

$$
D=\left(A k_{2} \varepsilon_{r} \varepsilon_{0}\right)^{2} / \tau_{2}
$$

Here, $k_{2}$ can be extracted from the impedance where $k_{2}$ is inverse to $C_{2}$, and $\tau_{2}$ is taken from the $Z_{i}$ minimum. Fadzallah et al. [50] stated that the value of $\varepsilon_{r}$ can be determined where $\log \varepsilon_{r}$ is constant. For impedance plots with a spike only, the value of $D$ can be determined from

$$
\begin{gathered}
D=D_{o} \exp \left\{-0.0297\left[\ln D_{o}\right]^{2}-1.4348\left[\ln D_{o}\right]-14.504\right\} \\
D_{o}=\left(4 k^{4} d^{2}\right) \times\left(R_{b}^{4} \omega_{m}^{3}\right)^{-1}
\end{gathered}
$$

where $\omega_{m}$ stands for angular frequency associated with the minimum $Z_{i}$, while $k$ is the inverse of $C$ of the impedance fitting. In Figure 5, the Nyquist plot of SL1, SL2, and SL3 consists of a semi-circle and an inclined spike. Equation (12) is therefore used to calculate the value of $D$. According to Equation (12), by plotting the $\log \varepsilon_{r}$ vs. $\log f$, the constant value of $\varepsilon_{r}$ can be determined. Based on Figure $8, \varepsilon_{r}$ is obtained by $\log \varepsilon_{r}>5.5$. 


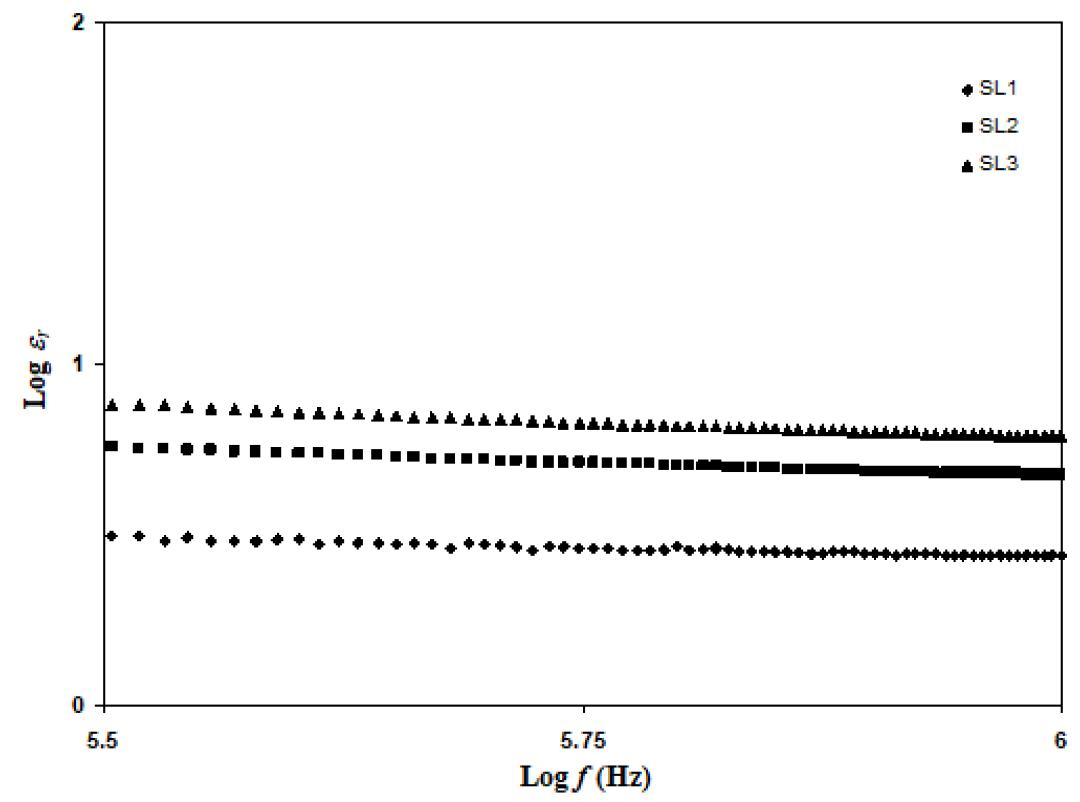

Figure 8. $\log \varepsilon_{r}$ vs. $\log f$ for SL1, SL2, and SL3.

Figure 9 displays the salted electrolyte's transport parameters at room temperature. In Figure 9a, the concentration of $\mathrm{NH}_{4} \mathrm{Br}$ increases from $5 \mathrm{wt} \%$ to $20 \mathrm{wt} \%$; it is observed that the value of $D$ increases from $3.65 \times 10^{-9} \mathrm{~cm}^{2} \mathrm{~s}^{-1}$ to $1.61 \times 10^{-8} \mathrm{~cm}^{2} \mathrm{~s}^{-1}$, respectively. However, when $25 \mathrm{wt} \%$ and $30 \mathrm{wt} \%$ of $\mathrm{NH}_{4}$ Brare added, the value of $D$ drops to $7.26 \times$ $10^{-9} \mathrm{~cm}^{2} \mathrm{~s}^{-1}$ and $5.02 \times 10^{-9} \mathrm{~cm}^{2} \mathrm{~s}^{-1}$, respectively. A similar pattern is observed for $\mu$ as displayed in Figure 9b, as the most conductive salted electrolyte (with $20 \mathrm{wt} \% \mathrm{NH}_{4} \mathrm{Br}$ ) has the highest value of $\mu\left(6.27 \times 10^{-7} \mathrm{~cm}^{2} \mathrm{~V}^{-1} \mathrm{~s}^{-1}\right)$. In Figure 9c, it is observed that the value of $n$ at $20 \mathrm{wt} \% \mathrm{NH}_{4} \mathrm{Br}$ achieved the maximum value of $1.58 \times 10^{21} \mathrm{~cm}^{-3}$. The $n$ value decreases as the concentration of $\mathrm{NH}_{4} \mathrm{Br}$ reaches $25 \mathrm{wt} \%$. This shows that the ionic conductivity trend at room temperature for the salted electrolyte is aligned with the trend of $D, \mu$, and $n$. Hence, it can be concluded that the decrement of the transport parameters at a high salt content is relatively caused by the close distance between the cations and anions, which leads to the reduction in the number density of the ion and ionic conductivity [51]. Figure 10 displays the transport parameters for SL4 at various temperatures. Figure 10a shows that the $D$ value increases from $1.61 \times 10^{-8} \mathrm{~cm}^{2} \mathrm{~s}^{-1}$ to $4.97 \times 10^{-8} \mathrm{~cm}^{2} \mathrm{~s}^{-1}$ as the temperature increases from $298 \mathrm{~K}$ to $343 \mathrm{~K}$. The same pattern for $\mu$ is obtained, whose maximum value is observed in Figure $10 \mathrm{~b}$ at $1.68 \times 10^{-6} \mathrm{~cm}^{2} \mathrm{~V}^{-1} \mathrm{~s}^{-1}$. It is visible from Figure 10c that the value of $n$ increases from $1.58 \times 10^{21} \mathrm{~cm}^{-3}$ to $2.51 \times 10^{21} \mathrm{~cm}^{-3}$. This segment of polymers vibrates at high temperatures, resulting in free volume enhancement. This volume allows ion pairs to dissociate and form free ions that indirectly increase the diffusivity and mobility of ions. 

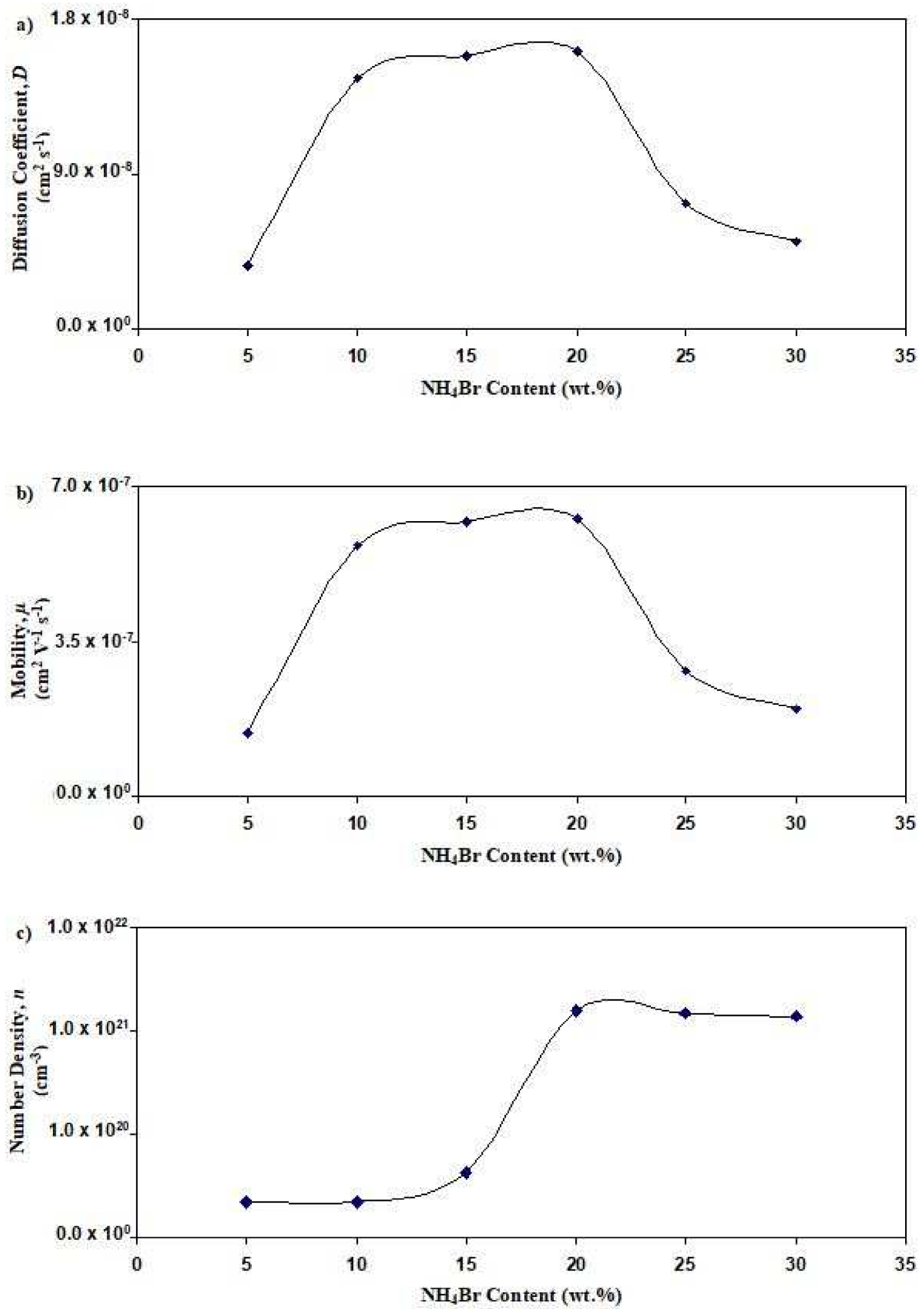

Figure 9. Graph of (a) $D,(\mathbf{b}) \mu$, and (c) $n$ for the salted electrolytes at room temperature. 

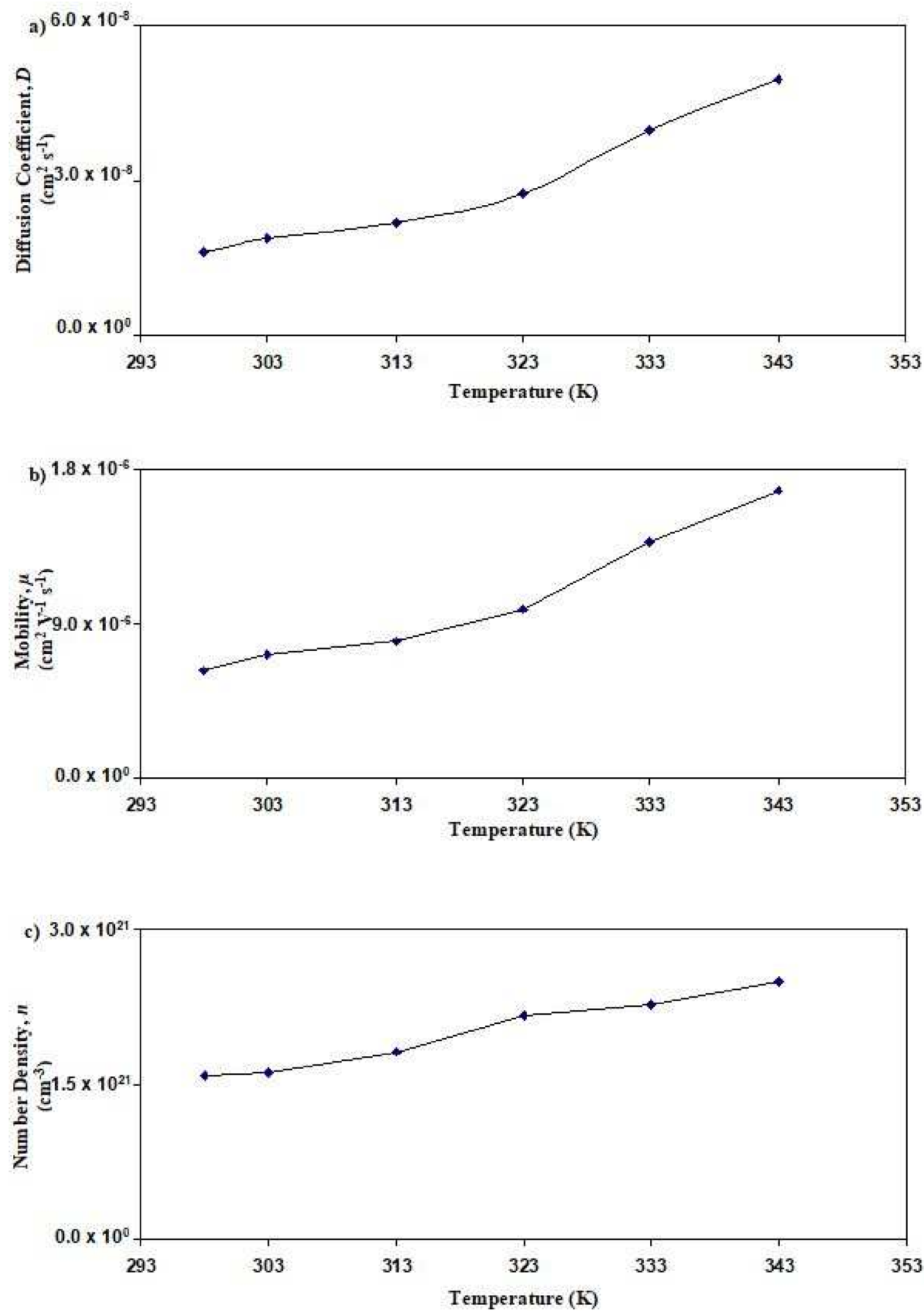

Figure 10. Graph of (a) $D$, (b) $\mu$, and (c) $n$ for the SL4 electrolytes at various temperatures.

\subsection{Linear Sweep Voltammetry (LSV)}

A linear sweep voltammetry (LSV) study is an essential tool used to check the suitability of the electrolyte in electrochemical device applications. Figure 11 displays the LSV plot 
for SL4. There are no apparent changes in the current value at a potential less than $1.7 \mathrm{~V}$ as the potentials are swept linearly from 0 to $3 \mathrm{~V}$. This means that SL4 is electrochemically stable up to $1.7 \mathrm{~V}$ [52]. The increase in current over $1.7 \mathrm{~V}$ is due to the electrolyte decomposition at the surface of the inert electrode [53]. Aziz et al. [54] reported an ammonium salt-based biopolymer electrolyte, where it started to decompose at $1.27 \mathrm{~V}$. This finding is very similar to other polymer electrolytes with an ammonium salt. Electrochemical stability up to $1.6 \mathrm{~V}$ has been reported by Noor and Isa [55] for a polymer electrolyte system of $\mathrm{CMC}$ doped with $\mathrm{NH}_{4} \mathrm{SCN}$. The CS-NH $\mathrm{NH}_{4} \mathrm{I}-\mathrm{Zn}$-glycerol system is reported to be potentially stable up to $1.37 \mathrm{~V}$ [53]. As a consequence of this finding, it can be stated that the highest conducting electrolyte provides sufficient potential stability for the use of energy storage devices.

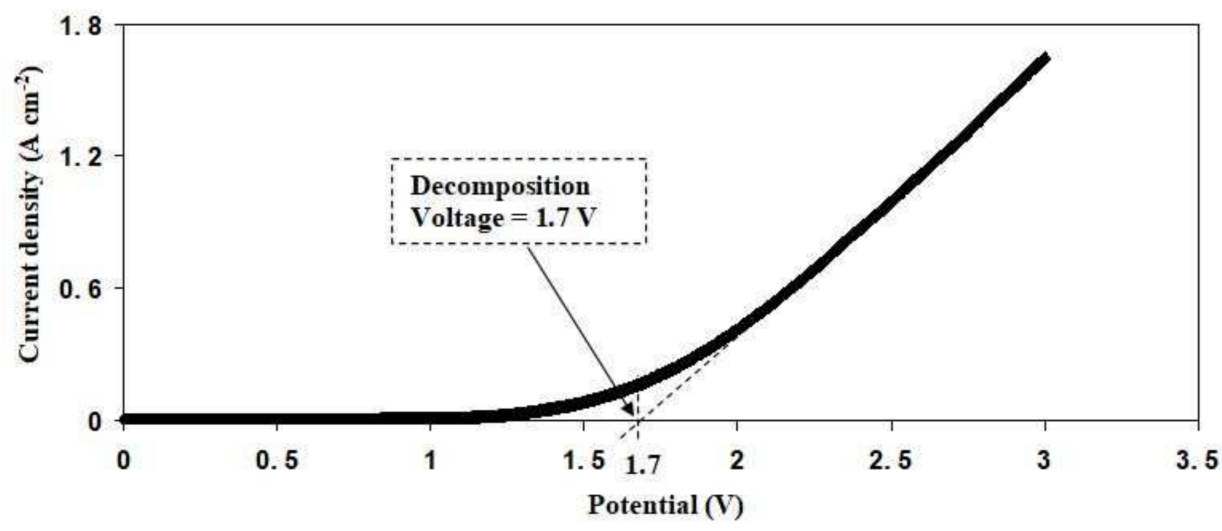

Figure 11. LSV curve for the SL4 electrolyte.

\subsection{Cyclic Voltammetry (CV)}

Cyclic voltammetry (CV) analysis has been used to test the EDLC fabricated using SL4. The CV curve for the fabricated EDLC is shown in Figure 12 at a series of scan rates. It is observed that redox reactions do not occur in the potential range between 0 and 0.9 $\mathrm{V}$, as the peaks that indicate that situation is absent. This situation tallies with the energy storage mechanism of an EDLC [56]. It is noticeable that as the scan rate decreases, the CV shape shifts from a leaf shape to nearly a rectangular shape. Kant et al. [57] mentioned that the rectangular $\mathrm{CV}$ curve indicates a good charge transport. The specific capacitance $\left(\mathrm{C}_{\mathrm{CV}}\right)$ of the EDLC can be obtained from the CV curve using the following equation:

$$
C_{C V}=\int_{V_{i}}^{V_{f}} \frac{I(V) d V}{2 m a\left(V_{f}-V_{i}\right)}
$$

where the area of the CV curve $\left(\int I(V) d V\right)$ in $\mathrm{cm}^{2}$ is extracted using the integration feature of Origin 8.5 software. The scan rate in $\mathrm{V} / \mathrm{s}$ is represented by $a$, while the mass of the activated material with gram $(\mathrm{g})$ is represented by $m . \mathrm{V}_{\mathrm{f}}$, and $\mathrm{V}_{\mathrm{i}}$, respectively, representing the final voltage of $0.9 \mathrm{~V}$ and the initial voltage of $0 \mathrm{~V}$. Table 7 shows the calculated values of $C_{C V}$. As the scan rate decreases, the $C_{C V}$ value increases. Ions can form proper Helmholtz layers at the surface of activated carbon electrodes at low scan rates. At higher scan rates, some ions undergo recombination and the transportation of ions is unstable, thus providing a low capacitance value $[58,59]$. 


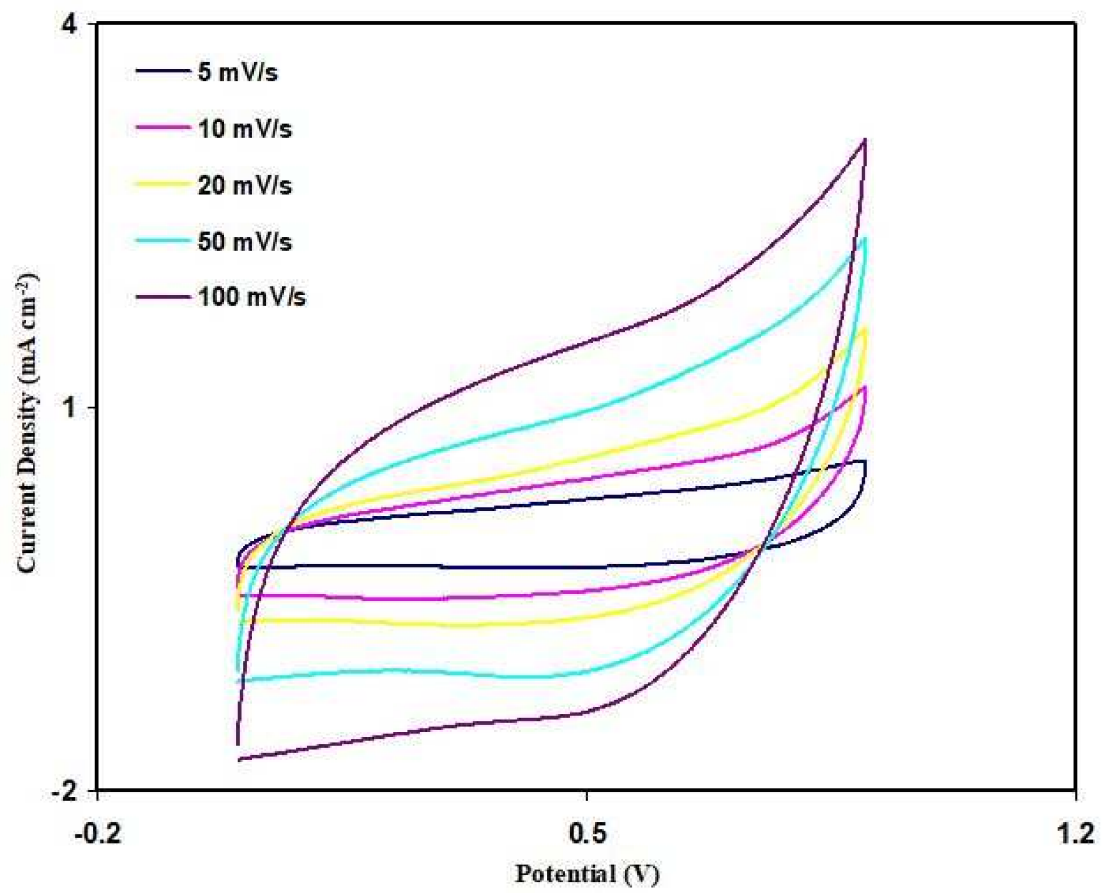

Figure 12. Cyclic voltammetry (CV) curve of the developed electrical double-layer capacitor (EDLC) for the SL4 film.

Table 7. Capacitance values from cyclic voltammetry (CV) against scan rates.

\begin{tabular}{cc}
\hline Scan Rates $\left(\mathbf{m V ~ s} \mathbf{~}^{-\mathbf{1}}\right)$ & Capacitance $\left(\mathbf{F ~}^{-\mathbf{1}}\right)$ \\
\hline 100 & 9.51 \\
50 & 13.41 \\
20 & 20.84 \\
10 & 29.70 \\
5 & 36.69 \\
\hline
\end{tabular}

\subsection{Dex-HEC-NH$H_{4} B r$-Based EDLC}

At $0.25 \mathrm{~mA} \mathrm{~cm}^{-2}$ and a potential range of 0 to $0.9 \mathrm{~V}$, the EDLC's rechargeability is tested for 8000 cycles. Figure 13 shows the EDLC's charge-discharge plot. The EDLC's capacitive behavior can be seen by the discharge slope, which is nearly linear [60]. Since the slope of the discharge curve (s) is known, the specific capacitance $\left(C_{C D}\right)$ can be calculated using the following equation:

$$
C_{C D}=\frac{i}{s m}
$$

where $i$ is the constant current. Figure 14a shows the $C_{C D}$ of the EDLC where the 1st cycle is $31.7 \mathrm{~F} \mathrm{~g}^{-1}$. This value is comparable to the one obtained from $\mathrm{CV}$ analysis. The $C_{C D}$ increases to $42.8 \mathrm{~F} \mathrm{~g}^{-1}$ as the cycle number reaches the 30 th cycle but reduces to $12.4 \mathrm{~F} \mathrm{~g}^{-1}$ until 450th cycles. Some ions are recombined in the rapid charge and discharge process creating ion pairs or aggregations. Ion pairs or aggregations block the conduction of ions, thus reducing the value of the capacitance [61]. It is common in EDLC that at the beginning cycles the performance is unstable as cations and anions are still trying to recognize the polarization pattern. The stabilization of $C_{C D}$ can be observed from 450th to the 8000th cycle with an average of $13.1 \mathrm{~F} \mathrm{~g}^{-1}$. Table 8 shows EDLC reported in other works with their respective parameters. 


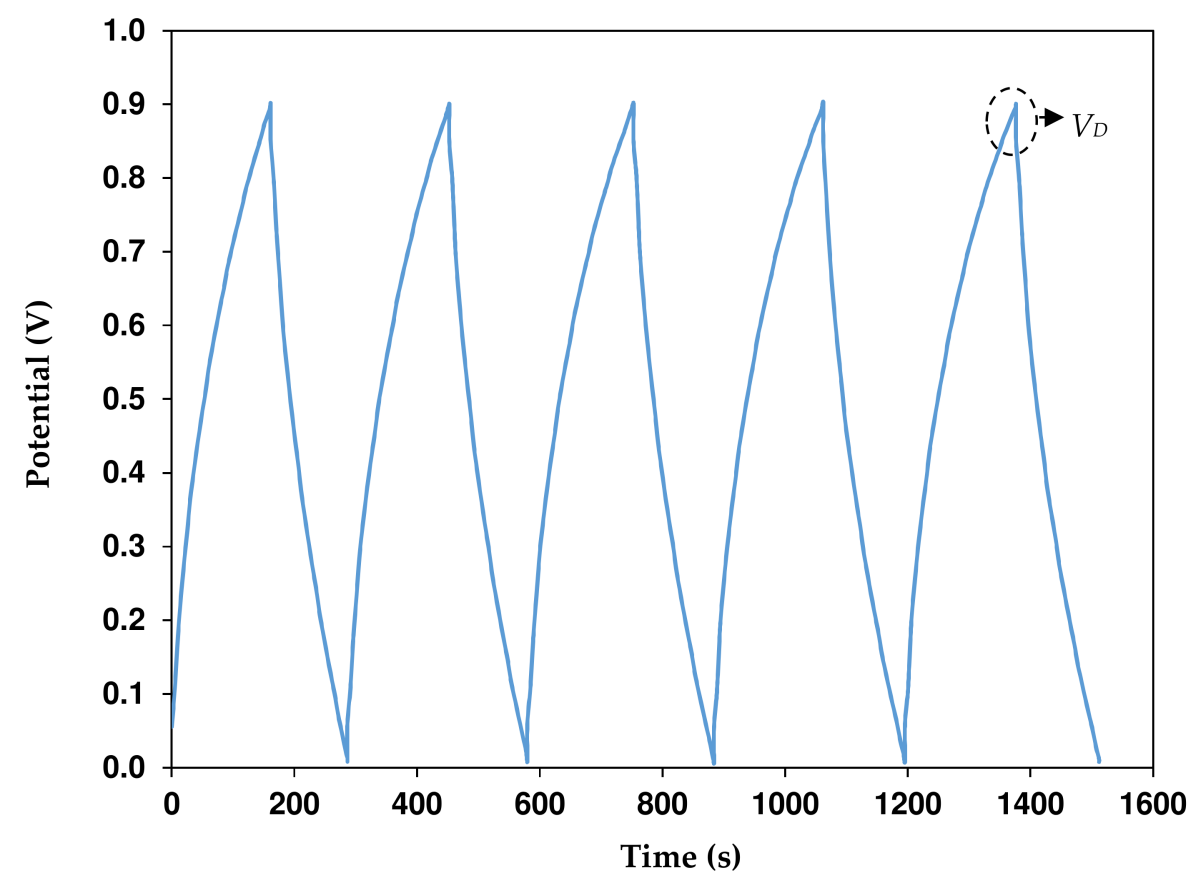

Figure 13. Charge-discharge profiles for the EDLC at $0.25 \mathrm{~mA} \mathrm{~cm}^{-2}$.

The ideal charge-discharge curve is similar to a triangular shape. However, the poor triangular shape could be due to the roughness of the carbon electrode, the type of electrolytes, and the internal resistance. As shown in Figure 13, the discharge process is started by a slight potential drop $\left(V_{D}\right)$. It can be linked to internal resistance in the EDLC, which is called the equivalent series resistance $\left(R_{E S R}\right)$. Based on the following equation, we can obtain the $R_{E S R}$ :

$$
R_{E S R}=\frac{V_{D}}{i}
$$

Figure $14 \mathrm{~b}$ shows the $R_{E S R}$ of the EDLC for 8000 cycles and it varies from 80 to $880 \Omega$. To begin, a double-layer charge or potential energy might emerge in the gap between the electrolyte and the electrode. The presence of ions from the electrolyte and electrons from the carbon electrode results in a double-layer charge [62]. Second, it is from the electrolyte itself that the fast charge/discharge process induces recombination of free ions and reduces the ionic conductivity. Finally, it is the current collectors. In this case, it is aluminum foil.

Table 8. Various reported activated carbon-based EDLC studies with their respective value of specific capacitance.

\begin{tabular}{|c|c|c|c|c|}
\hline Polymer Electrolyte & Current Density & $C_{C D}(\mathrm{~F} / \mathrm{g})$ & Cycles & Reference \\
\hline Dex- $\mathrm{NH}_{4} \mathrm{Br}$ & $0.063 \mathrm{~mA} / \mathrm{cm}^{2}$ & 2.05 & 100 & [52] \\
\hline $\mathrm{HEC}-\mathrm{MgTf}_{2}$-EMIMTf-SiO ${ }_{2}$ & $0.400 \mathrm{~A} / \mathrm{g}$ & 25.00 & 1600 & [63] \\
\hline CS-MC-NH ${ }_{4}$ I-Gly & $0.400 \mathrm{~mA} / \mathrm{cm}^{2}$ & 9.70 & 100 & [64] \\
\hline PVA-Dex-NH $4 \mathrm{I}$ & $0.500 \mathrm{~mA} / \mathrm{cm}^{2}$ & 4.20 & 100 & [53] \\
\hline PVA-LiClO $4-\mathrm{TiO}_{2}$ & - & 12.50 & 1000 & [65] \\
\hline PVA-Naft-BmImBr & $0.200 \mathrm{~A} / \mathrm{g}$ & 16.32 & 1000 & [66] \\
\hline PS-MC-NH $\mathrm{NO}_{3}$-Gly & $0.200 \mathrm{~mA} / \mathrm{cm}^{2}$ & 31.00 & 1000 & [67] \\
\hline Dex-HEC-NH $4{ }_{4} \mathrm{Br}$ & $0.250 \mathrm{~mA} / \mathrm{cm}^{2}$ & 31.70 & 8000 & This work \\
\hline
\end{tabular}

The energy density $\left(E_{D}\right)$ of the EDLC can be expressed as

$$
E_{D}=\frac{C_{C D} V}{2}
$$


where $V$ is the applied voltage $(0.9 \mathrm{~V}) . E_{D}$ is found to be $3.18 \mathrm{Wh} \mathrm{kg}^{-1}$ in the 1 st cycle in Figure 14c. The stabilization can be observed as soon as the cycle number reaches 450 where it fluctuates with an average of $1.31 \mathrm{Wh} \mathrm{kg}^{-1}$ up to the 8000th cycle. The pattern of $E_{D}$ is harmonized with the pattern of $C_{C D}$. This stabilization of the $E_{D}$ values indicates that the ions face the same energy barrier during migration towards the electrodes from 450th to 8000 th cycle. [32] Another crucial parameter of the EDLC is power density $\left(P_{D}\right)$ which can be determined using:

$$
P_{D}=\frac{V^{2}}{4 m R_{E S R}}
$$

As shown in Figure 14d, the value of $P_{D}$ is plotted up to 8000 cycles. In the 1st cycle, the value of $P_{D}$ is $922.22 \mathrm{~W} \mathrm{~kg}^{-1}$, but it decreases down to $319.6 \mathrm{~W} \mathrm{~kg}^{-1}$ at the 150 th cycle. The $P_{D}$ then further reduces to $158.4 \mathrm{~W} \mathrm{~kg}^{-1}$ at the 450 th cycle before it become constant at an average of $109 \mathrm{~W} \mathrm{~kg}^{-1}$. This may be linked to the electrolyte depletion and growth of ion aggregates/pairs during the quick charge-discharge process. Ion aggregates/pairs are the critical drawbacks of polymer electrolyte membranes. As a result, the accumulated ion in the double-layer formed at the surface of the electrodes is lowered and thus the power density is decreased [56].

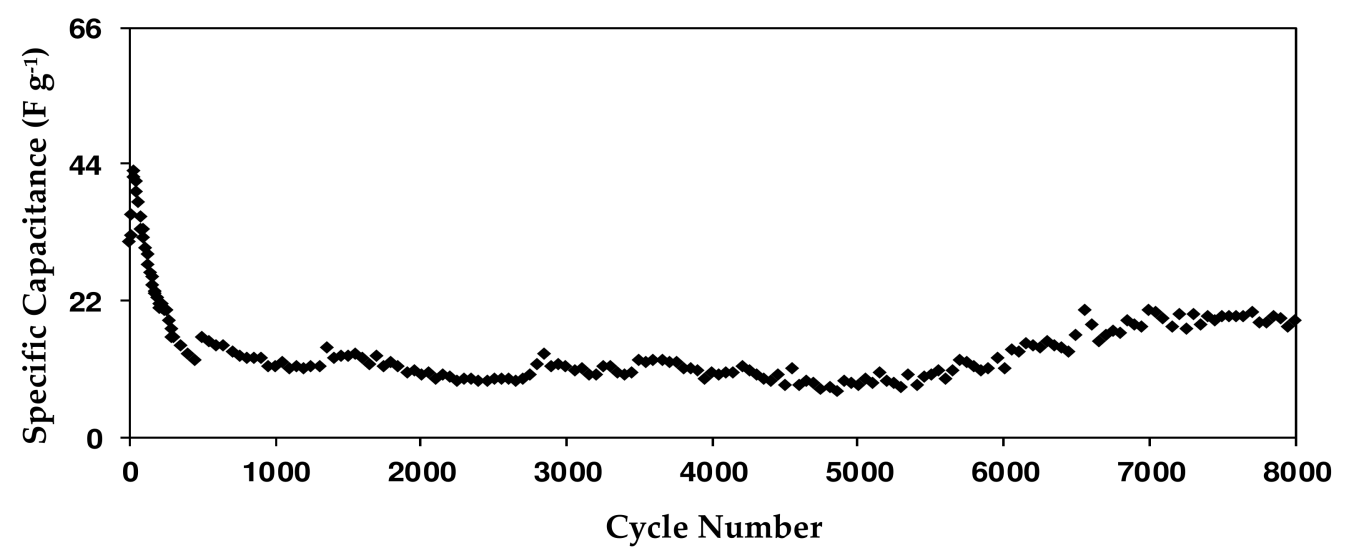

(a)

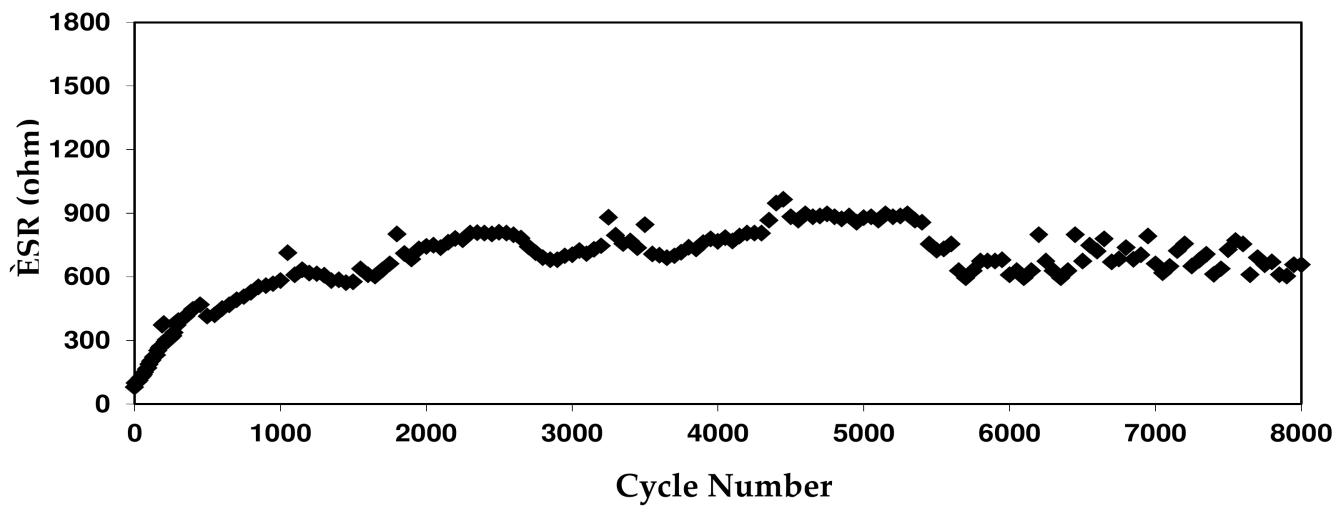

Figure 14. Cont. 


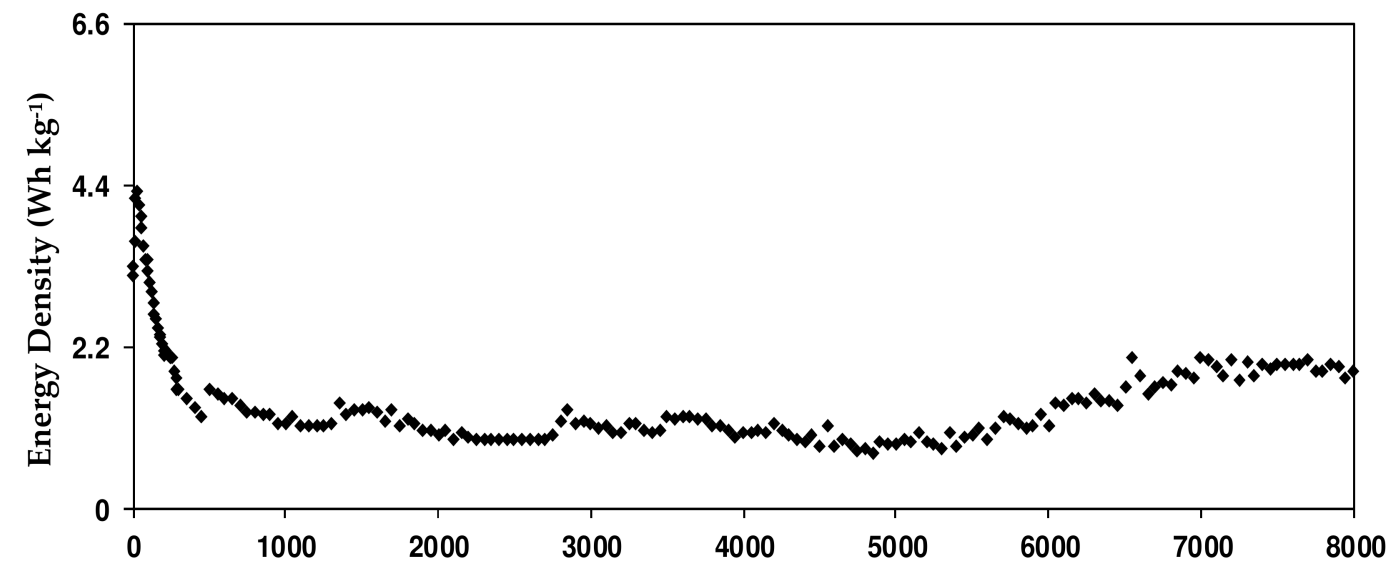

(c)

Cycle Number

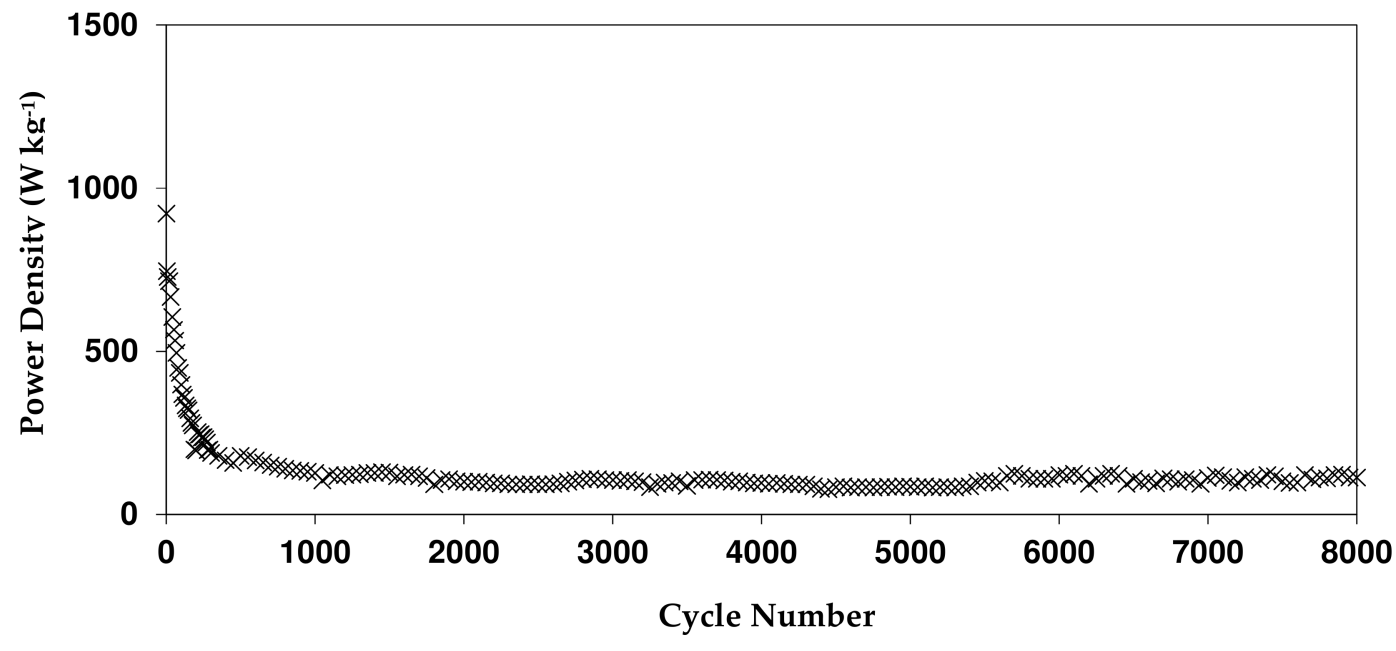

(d)

Figure 14. EDLC parameters: (a) specific capacitance, (b) equivalent series resistance, (c) energy density, and (d) power density of the EDLC for 8000 cycles.

\section{Conclusions}

The solid polymer electrolyte systems based on a Dex-HEC blend and doped with ammonium bromide $\left(\mathrm{NH}_{4} \mathrm{Br}\right)$ were effectively prepared viathe solution casting technique. The $40 \mathrm{wt} \%$ Dex-60 wt $\%$ HEC blend has the most suitable polymer host ratio. A $20 \mathrm{wt} \%$ $\mathrm{NH}_{4} \mathrm{Br}$ increased the conductivity to up to $(1.47 \pm 0.12) \times 10^{-4} \mathrm{~S} \mathrm{~cm}^{-1}$. The number density and mobility of ions in the highest conducting electrolyte (SL4) were $1.58 \times 10^{21} \mathrm{~cm}^{-3}$ and $6.27 \times 10^{-7} \mathrm{~V}^{-1} \mathrm{~s}^{-1} \mathrm{~cm}^{2}$, respectively. Up to $1.7 \mathrm{~V}$, the electrolyte is potentially stable. The EDLC's specific capacitance and energy density were stable at $13.1 \mathrm{~F} \mathrm{~g}^{-1}$ and $1.31 \mathrm{Wh} \mathrm{kg}^{-1}$, respectively. Even though the EDLC has been subjected to rapid charge-discharge, there are no extreme changes in the internal resistance value. The pattern of power density is highly related to the ESR, where it becomes constant at $109 \mathrm{~W} \mathrm{~kg}^{-1}$. The performance of the EDLC at a cycle below 450 is unstable because ions in the electrolyte are still in the process of recognizing the pattern of adsorption/desorption and conduction. Thus, it can be concluded that the Dex-HEC-NH${ }_{4}$ Br-based EDLC has shown an excellent performance. A plasticizer or filler can be added to the electrolyte to enhance the ionic conductivity for future improvement. The procedure and materials used in electrode fabrication can be modified to enhance the EDLC's performance. 
Author Contributions: Conceptualization, S.B.A., M.F.Z.K. and M.S.; Data curation, Z.I.Z. and Z.M.E.-B.; Formal analysis, E.M.A.D.; Funding acquisition, E.M.A.D. and M.M.N.; Investigation, M.A.S.A.; Methodology, M.A.S.A.; Project administration, S.B.A., M.F.Z.K., Z.I.Z. and M.S.; Supervision, M.F.Z.K. and M.S.; Validation, E.M.A.D., M.F.Z.K., Z.I.Z., Z.M.E.-B. and M.M.N.; Writingoriginal draft, M.A.S.A.; Writing-review \& editing, S.B.A., M.F.Z.K., Z.I.Z., Z.M.E.-B., M.S. and M.M.N. All authors have read and agreed to the published version of the manuscript.

Funding: This research was funded by VOCO GmbH, grant number BGAAF-1683.

Institutional Review Board Statement: Not applicable.

Informed Consent Statement: Not applicable.

Data Availability Statement: Data is contained within the article.

Acknowledgments: The authors would like to thank the University of Malaya for the facilities provided and grant Fundamental Research Grant Scheme (FP039-2019A). This work was financially supported by the Taif Researchers Supporting Project (TURSP-2020/42), Taif University, Taif, Saudi Arabia. We would like to acknowledge all support for this work by the University of Sulaimani, University of Malaya and Komar University of Science and Technology.

Conflicts of Interest: The authors declare no conflict of interest.

\section{References}

1. Iqbal, M.Z.; Rafiuddin, S. Structural, electrical conductivity and dielectric behavior of $\mathrm{Na}_{2} \mathrm{SO}_{4}-\mathrm{LDT}$ composite solid electrolyte. J. Adv. Res. 2016, 7, 135-141. [CrossRef]

2. Tomboc, G.M.; Kim, H. Derivation of both EDLC and pseudocapacitance characteristics based on synergistic mixture of $\mathrm{NiCo}_{2} \mathrm{O}_{4}$ and hollow carbon nanofiber: An efficient electrode towards high energy density supercapacitor. Electrochim. Acta 2019, 318, 392-404. [CrossRef]

3. Amran, N.N.A.; Manan, N.S.A.; Kadir, M.F.Z. The effect of $\mathrm{LiCF}_{3} \mathrm{SO}_{3}$ on the complexation with potato starch-chitosan blend polymer electrolytes. Ionics 2016, 22, 1647-1658. [CrossRef]

4. Arya, A.; Sharma, A.L. Polymer electrolytes for lithium ion batteries: A critical study. Ionics 2017, 23, 497-540. [CrossRef]

5. Salleh, N.S.; Aziz, S.B.; Aspanut, Z.; Kadir, M.F.Z. Electrical impedance and conduction mechanism analysis of biopolymer electrolytes based on methyl cellulose doped with ammonium iodide. Ionics 2016, 22, 2157-2216. [CrossRef]

6. Li, H.; Han, C.; Huang, Y.; Huang, Y.; Zhu, M.; Pei, Z.; Zhi, C. An extremely safe and wearable solid-state zinc ion battery based on a hierarchical structured polymer electrolyte. Energy Environ. Sci. 2018, 11, 941-951. [CrossRef]

7. Du, B.W.; Hu, S.Y.; Singh, R.; Tsai, T.T.; Lin, C.C.; Ko, F.U. Eco-friendly and biodegradable biopolymer chitosan $/ \mathrm{Y}_{2} \mathrm{O}_{3}$ composite materials in flexible organic thin-film transistors. Materials 2017, 10, 1026. [CrossRef] [PubMed]

8. Azli, A.A.; Manan, N.S.A.; Kadir, M.F.Z. The development of $\mathrm{Li}^{+}$conducting polymer electrolyte based on potato starch/graphene oxide blend. Ionics 2017, 23, 411-425. [CrossRef]

9. Yusof, Y.M.; Illias, H.A.; Shukur, M.F.; Kadir, M.F.Z. Characterization of starch-chitosan blend-based electrolyte doped with ammonium iodide for application in proton batteries. Ionics 2017, 23, 681-697. [CrossRef]

10. Chong, M.Y.; Numan, A.; Liew, C.-W.; Ramesh, K.; Ramesh, S. Comparison of the performance of copper oxide and yttrium oxide nanoparticle based hydroxylethyl cellulose electrolytes for supercapacitors. J. Appl. Polym. Sci. 2017, 134, 44636. [CrossRef]

11. Zhang, M.Y.; Li, M.X.; Chang, Z.; Wang, Y.F.; Gao, J.; Zhu, Y.S.; Wu, Y.P.; Huang, W. A sandwich PVDF/HEC/PVDF gel polymer electrolyte for lithium ion battery. Electrochim. Acta 2017, 245, 752-759. [CrossRef]

12. Li, M.X.; Wang, X.W.; Yang, Y.Q.; Chang, Z.; Wu, Y.P.; Holze, R. A dense cellulose-based membrane as a renewable host for gel polymer electrolyte of lithium ion batteries. J. Membr. Sci. 2015, 476, 112-118. [CrossRef]

13. Selvanathan, V.; Halim, M.N.A.; Azzahari, A.D.; Rizwan, M.; Shahabudin, N.; Yahya, R. Effect of polar aprotic solvents on hydroxyethyl cellulose-based gel polymer electrolyte. Ionics 2018, 24, 1955-1964. [CrossRef]

14. Tiwari, S.; Patil, R.; Bahadur, P. Polysaccharide based scaffolds for soft tissue engineering applications. Polymers 2019, 11, 1. [CrossRef]

15. Sirisha, V.L.; Souza, J.; Kim, S.-K. Marine OMICS: Principles and Applications; Marine Foodomics; CRC Press: Boca Raton, FL, USA, 2016; pp. 643-682.

16. Netsopa, S.; Niamsanit, S.; Sakloetsakun, D.; Milintawisamai, D. Characterization and rheological behavior of dextran from weissellaconfusa R003. Int. J. Polym. Sci. 2018, 2018, 1-10. [CrossRef]

17. Aziz, S.B.; Hadi, J.M.; Elham, E.M.; Abdulwahid, R.T.; Saeed, S.R.; Marf, A.S.; Karim, W.O.; Kadir, M.F.Z. The study of plasticized amorphous biopolymer blend electrolytes based on polyvinyl alcohol (PVA): Chitosan with high ion conductivity for energy storage electrical double-layer capacitors (EDLC) device application. Polymers 2020, 12, 1938. [CrossRef]

18. Rajendran, S.; Mahendran, O. Experimental investigations on plasticized PMMA/PVA polymer blend electrolytes. Ionics 2001, 7, 463-468. [CrossRef] 
19. Shukur, M.F.; Kadir, M.F.Z. Electrical and transport properties of NH4Br-doped cornstarch-based solid biopolymer electrolyte. Ionics 2015, 21, 111-124. [CrossRef]

20. Shukur, M.F.; Majid, N.A.; Ithnin, R.; Kadir, M.F.Z. Effect of plasticization on the conductivity and dielectric properties of starch-chitosan blend biopolymer electrolytes infused with $\mathrm{NH}_{4}$ Br. Phys. Scr. 2013, 57, 014051-014057. [CrossRef]

21. Nayak, R.; Dey, T.; Ghosh, P.; Bhattacharyya, A.R. Phosphoric acid doped poly(2,5-benzimidazole)-based proton exchange membrane for high temperature fuel cell application. J. Polym. Eng. Sci. 2016, 56, 20-25. [CrossRef]

22. Pujiastuti, S.; Onggo, H. Effect of various concentration of sulfuric acid for Nafion membrane activation on the performance of fuel cell. AIP Conf. Proc. 2016, 1711, 060006.

23. Hemalatha, R.; Alagar, M.; Selvasekarapandian, S.; Sundaresan, B.; Moniha, V.; Boopathi, G.; Selvin, P.C. Preparation and characterization of proton-conducting polymer electrolyte based on $\mathrm{PVA}$, amino acid proline, and $\mathrm{NH}_{4} \mathrm{Cl}$ and its applications to electrochemical devices. Ionics 2019, 25, 141-154. [CrossRef]

24. Aziz, S.B.; Dannoun, E.M.A.; Hamsan, M.H.; Ghareeb, H.O.; Nofal, M.M.; Karim, W.O.; Asnawi, A.S.F.M.; Hadi, J.M.; Kadir M.F.Z.A. A polymer blend electrolyte based on cs with enhanced ion transport and electrochemical properties for electrical double layer capacitor applications. Polymers 2021, 13, 930. [CrossRef]

25. Vijaya, N.; Selvasekarapandian, S.; Hirankumar, G.; Karthikeyan, S.; Nithya, H.; Ramya, C.S.; Prabu, M. Structural, vibrational, thermal, and conductivity studies on proton-conducting polymer electrolyte based on poly ( $N$-vinylpyrrolidone). Ionics 2012, 18, 91. [CrossRef]

26. Hafiza, M.N.; Bashirah, A.N.A.; Bakar, N.Y.; Isa, M.I.N. Electrical properties of carboxyl methylcellulose/chitosan dual-blend green polymer doped with ammonium bromide. Int. J. Polym. Anal. Charact. 2014, 19, 151-158. [CrossRef]

27. Hamsan, M.H.; Shukur, M.F.; Aziz, S.B.; Kadir, M.F.Z. Dextran from Leuconostocmesenteroides-doped ammonium salt-based green polymer electrolyte. Bull. Mater. Sci. 2019, 42, 57. [CrossRef]

28. Samsudin, A.S.; Isa, M.I.N. Structural and ionic transport study on CMC doped $\mathrm{NH}_{4} \mathrm{Br}$ : A new types of biopolymer electrolytes. J. Appl. Sci. 2012, 12, 174-179. [CrossRef]

29. Aziz, S.B.; Dannou, E.M.A.; Hamsan, M.H.; Abdulwahid, R.T.; Mishra, K.; Nofal, M.M.; Kadir, M.F.Z. Improving EDLC Device Performance Constructed from Plasticized Magnesium Ion Conducting Chitosan Based Polymer Electrolytes via Metal Complex Dispersion. Membranes 2021, 11, 289. [CrossRef]

30. Hadi, J.M.; Aziz, S.B.; Mustafa, M.S.; Hamsan, M.H.; Abdulwahid, R.T.; Kadir, M.F.Z.; Ghareeb, H.O. Role of nano-capacitor on dielectric constant enhancement in PEO:NH4SCN:xCeO2 polymer nano-composites: Electrical and electrochemical properties. J. Mater. Res. Technol. 2020, 9, 9283-9294. [CrossRef]

31. Marf, A.S.; Aziz, S.B.; Abdullah, R.M. Plasticized H+ ion-conducting PVA:CS-based polymer blend electrolytes for energy storage EDLC application. J. Mater. Sci. Mater. Electron. 2020, 31, 18554-18568. [CrossRef]

32. Hamsan, M.H.; Nofal, M.M.; Aziz, S.B.; Brza, M.A.; Dannou, E.M.A.; Murad, A.R.; Kadir, M.F.Z.; Muzakir, S.K. Plasticized Polymer Blend Electrolyte Based on Chitosan for Energy Storage Application: Structural, Circuit Modeling, Morphological and Electrochemical Properties. Polymer 2021, 13, 1233. [CrossRef]

33. Hanif, M.P.M.; Jalilah, A.J.; Badrul, F.; Nuraqmar, S.M.S. The influence of graphite on conductivity, crystallinity and tensile properties of hydroxyethyl cellulose (hec)/graphite composite films. IOP Conf. Ser. Mater. Sci. Eng. 2019, 701, 012015. [CrossRef]

34. Li, R.; Zhang, H.; Hu, X.; Gan, W.; Li, Q. An efficiently sustainable dextran-based flocculant: Synthesis, characterization and flocculation. Chemosphere 2016, 159, 342-450. [CrossRef]

35. Mohamed, A.S.; Shukur, M.F.; Kadir, M.F.Z.; Yusof, Y.M. Ion conduction in chitosan-starch blend based polymer electrolyte with ammonium thiocyanate as charge provider. J. Polym. Res. 2020, 27, 149. [CrossRef]

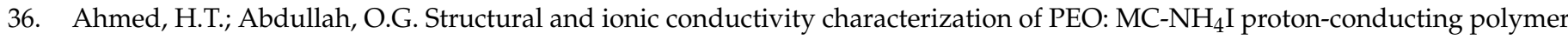
blend electrolytes based films. Results Phys. 2020, 16, 102861. [CrossRef]

37. Pandi, D.V.; Selvasekarapandian, S.; Bhuvaneswari, R.; Premalatha, M.; Monisha, S.; Arunkumar, D.; Junichi, K. Development

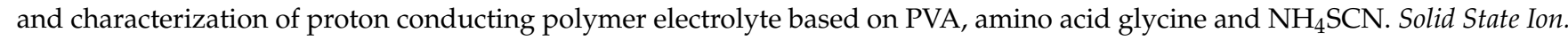
2016, 298, 15-22. [CrossRef]

38. Abdullah, O.G.; Aziz, S.B.; Rasheed, M.A. Incorporation of $\mathrm{NH}_{4} \mathrm{NO}_{3}$ into MC-PVA blend-based polymer to prepare protonconducting polymer electrolyte films. Ionics 2018, 24, 777-785. [CrossRef]

39. Sohaimy, M.I.H.; Isa, M.I.N. Ionic conductivity and conduction mechanism studies on cellulose based solid polymer electrolytes doped with ammonium carbonate. Polym. Bull. 2017, 74, 1371-1386. [CrossRef]

40. Mazuki, N.; Majeed, A.P.P.A.; Samsudin, A.S. Study on electrochemical properties of CMC-PVA doped $\mathrm{NH}_{4} \mathrm{Br}$ based solid polymer electrolytes system as application for EDLC. J. Polym. Res. 2020, 27, 135. [CrossRef]

41. Samsudin, A.S.; Khairul, W.M.; Isa, M.I.N. Characterization on potential of carboxy methylcellulose for application as proton conducting biopolymer electrolytes. J. Non-Cryst. Solids 2012, 358, 1104-1112. [CrossRef]

42. Kartha, S.A. A Preparation of B2O3-Li2O-MO (M=Pb, Zn) Glass Thin Films and Study of Thin Properties. Ph.D. Thesis, Mahatma Gandhi University, Kerala, India, 2013.

43. Shukur, M.F. Characterization of Ion Conducting Solid Bio-Polymer Electrolytes Based on Starch-Chitosan Blend and Application in Electrochemical Devices. Ph.D. Thesis, University of Malaya, Kuala Lumpur, Malaysia, 2015.

44. Yulianti, E.; Deswita, D.; Sudaryanto, S.; Mashadi, S. Study of solid polymer electrolyte based on biodegradable polymer polycaprolactone. Mal. J. Fund. Appl. Sci. 2019, 15, 467-471. 
45. Yao, P.; Yu, P.; Ding, Z.; Liu, Y.; Lu, J.; Lavorgna, M.; Wu, J.; Liu, X. Review on polymer-based composite electrolytes for lithium batteries. Front. Chem. 2019, 7, 1-17. [CrossRef] [PubMed]

46. Qian, X.; Gu, N.; Cheng, Z.; Yang, X.; Wang, E.; Dong, S. Impedance study of (PEO) ${ }_{10} \mathrm{LiClO}_{4}-\mathrm{Al}_{2} \mathrm{O}_{3}$ composite polymer electrolyte with blocking electrodes. Electrochim. Acta 2001, 46, 1829-1836. [CrossRef]

47. Kumar, M.S.; Rao, M.C. Effect of $\mathrm{Al}_{2} \mathrm{O}_{3}$ on structural and dielectric properties of PVP-CH${ }_{3} \mathrm{COONa}$ based solid polymer electrolyte films for energy storage devices. Heliyon 2019, 5, 1-10. [CrossRef] [PubMed]

48. Shuhaimi, N.E.A.; Teo, L.P.; Woo, H.J.; Majid, S.R.; Arof, A.K. Electrical double-layer capacitors with plasticized polymer electrolyte based on methyl cellulose. Polym. Bull. 2012, 69, 807-826. [CrossRef]

49. Arof, A.K.; Amirudin, S.; Yusof, S.Z.; Noor, I.M. A method based on impedance spectroscopy to determine transport properties of polymer electrolytes. Phys. Chem. 2014, 16, 1856-1867. [CrossRef] [PubMed]

50. Fadzallah, I.A.; Noor, I.M.; Careem, M.A.; Arof, A.K. Investigation of transport properties of chitosan-based electrolytes utilizing impedance spectroscopy. Ionics 2016, 22, 1635-1645. [CrossRef]

51. Ahmad, N.H.; Isa, M.I.N. Proton conducting solid polymer electrolytes based carboxymethyl cellulose doped ammonium chloride: Ionic conductivity and transport studies. Int. J. Plast. Technol. 2015, 19, 47-55. [CrossRef]

52. Hamsan, M.H.; Shukur, M.F.; Aziz, S.B.; Yusof, Y.M.; Kadir, M.F.Z. Influence of $\mathrm{NH}_{4} \mathrm{Br}$ as an ionic source on the structural/electrical properties of dextran-based biopolymer electrolytes and EDLC application. Bull. Mater. Sci. 2020, 43, 30. [CrossRef]

53. Hadi, J.M.; Aziz, S.B.; Saeed, S.R.; Brza, M.A.; Abdulwahid, R.T.; Hamsan, M.H.; Abdullah, R.M.; Kadir, M.F.Z.; Muzakir, S.K. Investigation of ion transport parameters and electrochemical performance of plasticized biocompatible chitosan-based proton conducting polymer composite electrolytes. Membranes 2020, 10, 363. [CrossRef]

54. Aziz, S.B.; Brza, M.A.; Mishra, K.; Hamsan, M.H.; Karim, W.O.; Abdullah, R.M.; Kadir, M.F.Z.; Abdulwahid, R.T. Fabrication of high performance energy storage EDLC device from proton conducting methylcellulose: Dextran polymer blend electrolytes. J. Mater. Res. Technol. 2020, 9, 1137-1150. [CrossRef]

55. Noor, N.A.M.; Isa, M.I.N. Investigation on transport and thermal studies of solid polymer electrolyte based on carboxymethyl cellulose doped ammonium thiocyanate for potential application in electrochemical devices. Int. J. Hydrog. Energy 2019, 44, 8298-8306. [CrossRef]

56. Liew, C.W.; Ramesh, S. Electrical, structural, thermal and electrochemical properties of corn starch-based biopolymer electrolytes. Carbohydr. Polym. 2015, 124, 222-228. [CrossRef] [PubMed]

57. Kant, R.; Singh, M.B. Theory of the electrochemical impedance of mesostructured electrodes embedded with heterogeneous micropores. J. Phys. Chem. C 2017, 121, 7164-7174. [CrossRef]

58. Shukur, M.F.; Hamsan, M.H.; Kadir, M.F.Z. Investigation of plasticized ionic conductor based on chitosan and ammonium bromide for EDLC application. Mater. Today Proc. 2019, 17, 490-498. [CrossRef]

59. Aziz, S.B.; Brza, M.A.; Dannoun, E.M.A.; Hamsan, M.H.; Hadi, J.M.; Kadir, M.F.Z.; Abdulwahid, R.T. The Study of Electrical and Electrochemical Properties of Magnesium Ion Conducting CS: PVA Based Polymer Blend Electrolytes: Role of Lattice Energy of Magnesium Salts on EDLC Performance. Molecules 2020, 25, 4503. [CrossRef]

60. Teoh, K.H.; Liew, C.W.; Ramesh, S. Electric double layer capacitor based on activated carbon electrode and biodegradable composite polymer electrolyte. Ionics 2014, 20, 251-258.

61. Teoh, K.H.; Lim, C.S.; Liew, C.W.; Ramesh, S. Electric double-layer capacitors with corn starch-based biopolymer electrolytes incorporating silica as filler. Ionics 2015, 21, 2061-2068. [CrossRef]

62. Arof, A.K.; Kufian, M.Z.; Syukur, M.F.; Aziz, M.F.; Abdelrahman, A.E.; Majid, S.R. Electrical double layer capacitor using poly(methyl methacrylate)-C4BO8Li gel polymer electrolyte and carbonaceous material from shells of matakucing (Dimocarpuslongan) fruit. Electrochim. Acta 2012, 74, 39-45. [CrossRef]

63. Chong, M.Y.; Numan, A.; Liew, C.W.; Ng, H.; Ramesh, K.; Ramesh, S. Enhancing the performance of green solid-state electric double-layer capacitor incorporated with fumed silica nanoparticles. J. Phys. Chem. Solids 2018, 117, 194-203. [CrossRef]

64. Aziz, S.B.; Hamsan, M.H.; Brza, M.A.; Kadir, M.F.Z.; Muzakir, S.K.; Abdulwahid, R.T. Effect of glycerol on EDLC characteristics of chitosan:methylcellulose polymer blend electrolytes. J. Mater. Res. Technol. 2020, 9, 8355-8366. [CrossRef]

65. Lim, C.S.; Teoh, K.H.; Liew, C.W.; Ramesh, S. Capacitive behavior studies on electrical double layer capacitor using poly (vinyl alcohol)-lithium perchlorate based polymer electrolyte incorporated with $\mathrm{TiO}_{2}$. Mater. Chem. Phys. 2014, 143, 661-667. [CrossRef]

66. Farah, N.; Ng, H.M.; Numan, A.; Liew, C.W.; Latip, N.A.A.; Ramesh, K.; Ramesh, S. Solid polymer electrolytes based on poly(vinyl alcohol) incorporated with sodium salt and ionic liquid for electrical double layer capacitor. Mater. Sci. Eng. B 2019, $251,114468$. [CrossRef]

67. Hamsan, M.H.; Shukur, M.F.; Kadir, M.F.Z. $\mathrm{NH}_{4} \mathrm{NO}_{3}$ as charge carrier contributor in glycerolized potato starch-methyl cellulose blend-based polymer electrolyte and the application in electrochemical double-layer capacitor. Ionics 2017, 23, 3429-3453. [CrossRef] 